\title{
An Improved Dispatch Strategy of a Grid-Connected Hybrid Energy System with High Penetration Level of Renewable Energy
}

\author{
Yan Zhang, ${ }^{1}$ Jie Meng, ${ }^{1}$ Bo Guo, ${ }^{1}$ and Tao Zhang ${ }^{1,2}$ \\ ${ }^{1}$ College of Information System and Management, National University of Defense Technology, Changsha, Hunan 410073, China \\ ${ }^{2}$ State Key Laboratory of High Performance Computing, National University of Defense Technology, Changsha, Hunan 410073, China \\ Correspondence should be addressed to Yan Zhang; zy331214534@126.com
}

Received 10 February 2014; Revised 2 April 2014; Accepted 2 April 2014; Published 24 June 2014

Academic Editor: Zhijun Zhang

Copyright (c) 2014 Yan Zhang et al. This is an open access article distributed under the Creative Commons Attribution License, which permits unrestricted use, distribution, and reproduction in any medium, provided the original work is properly cited.

\begin{abstract}
As more and more renewable energy sources (RES) integrated into the conventional distribution system, how to make the current electric grid more reliable and efficient is becoming an important topic the world must face. In order to achieve these goals, grid-connected hybrid energy systems (HES) which contain battery energy storage systems (BESS) and many other advanced technologies have been developed and applied. Many benefits of BESS, such as high density of energy and power, have fast response in energy time-shift, frequency regulation, and so on. This paper focuses on the fluctuation alleviation and power quality improvement of grid-connected HES with high penetration level of RES. A multistage dispatch strategy of BESS for HES is proposed in this paper to mitigate the randomness and intermittence of the power flowed in HES because of high penetration level of RES integration. Four other conventional strategies are also discussed for evaluating the performance of the method proposed in this paper. Detailed cases and corresponding discussions are implemented, and the results show that the method proposed in this paper is more effective and robust than the other conventional strategies.
\end{abstract}

\section{Introduction}

There is an unprecedented growth in power generation, delivery, and usage. HES integrated with environmental friendly energy sources (wind, solar, and alike) and energy storage system (EES) has drawn more and more attention in mitigating global warming effects, reducing fossil fuel dependence, and reducing economic impact from the rising oil prices [1].

Many governments such as Germany, France, USA, and China had recognized the benefits of RES, and much favorable legislation had been provided to incent large scale of RES installation and utilization $[2,3]$. Investigations show that RES has become the fastest growing source of electricity around the world in the past decade, and this tendency is expected to continue in the next two decades [4]. In the near future, HES with high penetration level of RES will be emerged in some district power systems. RES penetration level of California will reach 33\% in 2030 [5]; that of Yancheng city, Jiangsu province, $34 \%$ in 2017; and that of some regions of Inner Mongolia and Gansu province, almost 100\% [6].
As the penetration level of RES is increasing to an unprecedented pace, the properties of intermittency and fluctuation will arose some adverse effects for the operation of the power system, especially in weak power systems of remote area. If no suitable scheduling and operation strategy are implemented in the management of high penetration level of intermittent and stochastic RES, many negative impacts would be caused $[7,8]$.

Currently, a lot of researches concern themselves in characterization, planning, evaluation, and optimization of the HES, particularly in isolated HES of remote districts [911]. However, only a few focused on grid-connected HES of low penetration level of RES integration and mainly on cost/worth evaluation or economic analysis [12-14]. As the penetration level of RES grows, new operation and scheduling methods should be developed for power quality improving and RES full utilization. Authors in $[7,14]$ investigated the operation strategy of EES for distribution system and analyzed the benefits of their algorithms. Researchers in [15-17] presented some supervisory control methods to alleviate the fluctuations caused by RES integration; however, 


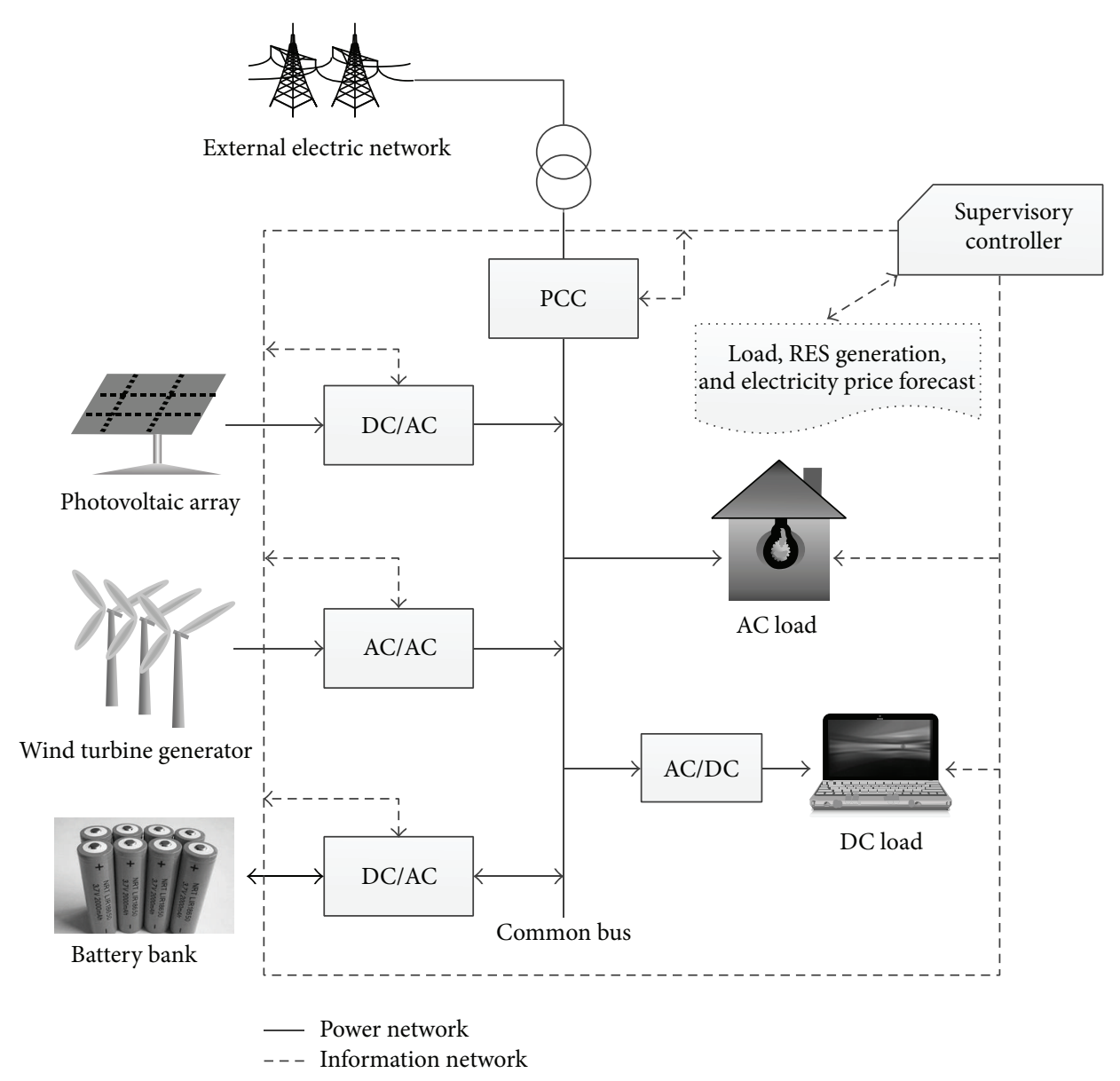

FIGURE 1: Schematic configuration of grid-connected HES.

their control methods are not flexible enough nor fully reflect the superiority of ESS either. In this paper, two main parts are concerned, namely, exploring one scheduling and operation method of BESS to alleviate fluctuations of the power flowed in grid-connected HES with high RES penetration level integration automatically, furthermore, analyzing the relationships among the system performance and BESS parameters (i.e., power limit, capacity limit), and forecast uncertainty of RES generation and load demand. For better evaluating the performances of the method prosed in this paper, four other strategies are discussed and simulated in the same condition.

In this paper, system description, modeling and constraints of grid-connected HES, indexes used for different strategies evaluation, and detailed mathematical models of strategies referred in this paper are presented to evaluate the performance of them in alleviating fluctuation and improving power quality of high RES penetration level HES. In order to well and truly depict the importance of BESS and dispatch strategy in HES, some discussions are implemented to analyze the relationships between BESS parameters and system performance in different strategies.

The rest of this paper is organized as follows. Section 2 describes the model of HES and constraints and evaluation indexes used in this paper; detailed mathematical models of all the strategies are presented in Section 3; cases, results, and discussions are shown in Section 4; this paper is concluded in Section 5.

\section{System Description and Modeling}

Fluctuation smoothing problem of grid-connected HES is similar to load shifting problem in bulk power system [12] but more complex than that, because RES power generation in HES is more random and oscillatory than load demand in bulk power system, and power generated by RES in gridconnected HES with high penetration level of RES could not be considered as negative load any more. Real-time power exchanged between grid-connected HES and the external grid is operated by a supervisory controller of HES based on specific HES operation strategy.

2.1. HES Schematic Model. Figure 1 presents the schematic topology of a grid-connected HES analyzed in this paper, which is consisted of some PV generators, wind turbine generators, EES (BESS considered in this paper), and a few of local consumers (controllable load/critical load). All the above units are controlled by a supervisory controller, and the energy management operation should consider the variation of local weather, load demand, electricity price, and so on [14]. 
The model of RES generators presented in Figure 1 of this paper could be illustrated as follows:

$$
\begin{gathered}
P_{\text {wind }}(k)= \begin{cases}0 & \text { if } v(k)<v_{\mathrm{ci}} \\
P_{\text {wind }} \max \cdot \frac{v(k)-v_{\mathrm{ci}}}{v_{r}-v_{\mathrm{ci}}}, & \text { if } v_{\mathrm{ci}} \leq v(k)<v_{r} \\
P_{\text {wind }} \max , & \text { if } v_{r} \leq v(k)<v_{\mathrm{co}} \\
0, & \text { if } v_{\mathrm{co}} \leq v(k),\end{cases} \\
P_{\text {solar }}(k)= \begin{cases}P_{\text {solar }} \max \left(\frac{G_{\mathrm{bt}}(k)^{2}}{G_{\mathrm{std}} R_{c}}\right), & \text { if } 0 \leq G_{\mathrm{bt}}(k)<R_{c} \\
P_{\text {solar }} \max \left(\frac{G_{\mathrm{bt}}(k)}{G_{\text {std }}}\right), & \text { if } R_{c} \leq G_{\mathrm{bt}}(k)<G_{\text {std }} \\
P_{\text {solar }} \max , & \text { if } G_{\mathrm{bt}}(k) \geq G_{\text {std }},\end{cases}
\end{gathered}
$$

where $P_{\text {solar }}$ max is the power output of PV generators in stand test situation and, at the point of $R_{c}$, the relations between PV power output and illumination intensity from nonlinearity to linearity and detailed model of wind and PV generators could be found in [18] and [19], respectively, and the references therein.

2.2. Modeling Assumptions. In order to depict the system and dispatch strategies of this paper sufficiently and exactly, the following assumptions and requirements should be implemented.

(i) The HES is in steady state all the time, the frequency and voltage levels are properly regulated.

(ii) Duration of two consequent periods is $15 \mathrm{~min}$ throughout this paper, namely, $\Delta t=15 \mathrm{~min}$, and the wind speed/solar irradiation/load demands are assumed to have no variation within one period.

(iii) All actions should be implemented simultaneously if control signals have been accepted.

(iv) Only the active power in HES is considered.

(v) Advanced communication network could support fast and reliable information transmission.

2.3. Constraints. To make the HES model perform efficiently, a set of restrictions also should be satisfied; they can be classified as follows.

(1) Energy balance constraint: at each period, load demand should be met with RES generation, BESS, or import power from the external grid:

$$
\begin{gathered}
P_{\text {grid }}(k)=Y(k)-P_{b}(k) \\
Y(k)=P_{\text {wind }}(k)+P_{\text {solar }}(k)-P_{\text {load }}(k) \\
k=1,2, \ldots, T,
\end{gathered}
$$

where $P_{\text {grid }}(k)>0$ represents HES exporting excess energy to external grid in period $k$; in the opposite case, energy is imported from the external grid. Similar to $P_{\text {grid }}(k), P_{b}(k)>0$ represents BESS charge power in period $k$, and in the opposite case, BESS discharge power to HES.

(2) BESS limits: the energy and power charging or discharging in each period could not go over the limit:

$$
\begin{aligned}
& \operatorname{Vol}_{b \text { min }} \leq \operatorname{Vol}_{b}(k) \leq \mathrm{Vol}_{b \max } \\
& \text { s.t. } \quad \operatorname{Vol}_{b \text { max }}=\alpha \cdot \mathrm{Vol}_{b}, \quad \mathrm{Vol}_{b \text { min }}=\beta \cdot \mathrm{Vol}_{b} \\
& -\min \left\{\left(\mathrm{Vol}_{b}(k)-\mathrm{Vol}_{b \min }\right), P_{b \text { max }} \Delta t\right\} \leq P_{b}(k) \Delta t \\
& \quad \leq \min \left\{\left(\mathrm{Vol}_{b \text { max }}-\mathrm{Vol}_{b}(k)\right), P_{b \text { max }} \Delta t\right\} \\
& -P_{b \max } \leq P_{b}(k) \leq P_{b \text { max }} \\
& \qquad k=1,2, \ldots, T,
\end{aligned}
$$

where $\alpha$ and $\beta$ are factors used to determine the upper and lower available BESS capacity limit, $0<\beta<$ $\alpha<1$, for better understanding this paper, some assumptions are implemented, there is no energy loss all over the time horizon, the efficiency of charging and discharging of the energy storage in this paper is 1 , namely the BESS operates perfectly, and no ramp rate limit of the BESS.

(3) Other constraints: some upper and lower power limits of RES generators and power transmission limit between HES and the external grid should be met:

$$
\begin{gathered}
0 \leq P_{\text {wind }}(k) \leq P_{\text {wind }} \max , \\
0 \leq P_{\text {solar }}(k) \leq P_{\text {solar }} \max , \\
-P_{\text {grid }} \max \leq P_{\text {grid }}(k) \leq P_{\text {grid }} \max , \\
0 \leq P_{\text {load }}(k) \leq P_{\text {load }} \max \\
k=1,2, \ldots, T,
\end{gathered}
$$

where we assume that the load in the grid-connected HES of this paper is inelastic, and no ramp-up or ramp-down power of wind and $\mathrm{PV}$ generators is considered.

2.4. Evaluation Indicators. Grid-connected HES plays an important role in improving power quality, mitigating power fluctuation, reducing transmission loss, improving power supply reliability, and integrating more RES. A few indicators such as standard variance of power transferred at PCC, RES net-use rate, BESS use rate, and peak power at PCC are constructed to help to effectively evaluate the performance of strategies referred to in this paper.

2.4.1. Standard Variance of Power Transferred at PCC. The main objective of this paper is to search a method which could alleviate the fluctuation and improve power quality in HES as much as possible. Hence, stand variance of power 
transferred at PCC could reflect this purpose appropriately, which is formulated as follows:

$$
\text { Var }=\frac{1}{T} \sum_{d=1}^{M} \sum_{j=1}^{N}\left[P_{\text {grid }}(j)-\frac{1}{N} \sum_{i=1}^{N} P_{\text {grid }}(i)\right]^{2}
$$

this formula reflects the randomness level of power flowed in HES [17]; if $\mathrm{Var}=0$, the performance of this method in alleviating fluctuation is perfect; otherwise, the greater Var is the more intensive fluctuation of the power flowed in HES.

2.4.2. RES Net-Use Rate. This indicator represents the level of excess energy generated by RES generators and stored by BESS and then used by HES when RES generation is insufficient, which is used to evaluate the availability of BESS in improving the utilization rate of RES generator for local use (i.e., increasing the consumer independence from the external grid). The detailed formula is shown as follows:

$$
\begin{aligned}
& \text { net_use_rate }=\text { use_rate }- \text { wasted_rate, } \\
& \text { use_rate }=\left(\sum_{k=1}^{T} \max \left(\frac{\max \left(P_{b}(k), 0\right)}{\max (Y(k), 0)+\varepsilon}, 0\right)\right. \\
& \\
&\cdot(Y(k)+\varepsilon)) \\
& \times\left(\sum_{k=1}^{T} \max (Y(k), 0)\right)^{-1}
\end{aligned}
$$

wasted_rate

$$
\begin{aligned}
= & \frac{\sum_{k=1}^{T} \max \left(\left(-\min \left(P_{b}(k), 0\right)+\min (Y(k), 0)\right), 0\right)}{\sum_{k=1}^{T} \max (Y(k), 0)} \\
& +\left(\sum_{k=1}^{T} \min \left(\frac{\min \left(P_{b}(k), 0\right)}{\max (Y(k), 0)+\varepsilon}, 0\right) \cdot(Y(k)+\varepsilon)\right) \\
& \times\left(\sum_{k=1}^{T} \max (Y(k), 0)\right)^{-1} \\
& +\frac{\sum_{k=1}^{T} \max \left(\max \left(P_{b}(k), 0\right)-\max (Y(k), 0), 0\right)}{\sum_{k=1}^{T} \max (Y(k), 0)} \\
& +\left(\sum_{k=1}^{T}\left(\frac{\max \left(P_{b}(k), 0\right)}{\min (Y(k), 0)+\varepsilon}, 0\right)\right. \\
& \times\left(\sum_{k=1}^{T} \max (Y(k), 0)\right)^{-1},
\end{aligned}
$$

where use_rate reflects the level of energy generated by RES and charged by BESS in the whole simulation horizon, which has close relation to BESS scheduling and operation strategy; waste_rate represents the level of RES energy stored in BESS but not utilized by local consumers in HES; as a whole, this indicator is consisted of four parts. The first term refers to the energy charged by BESS but purchased from the external grid; this may happen in maximum charging, maximum discharging, and multistage dispatch strategy; the secondary and third term denotes the energy overcharged from external grid when RES generation is enough to support HES's normal operation; these may occur in maximum charge and multistage dispatch strategy; the last term reflects the energy overcharged from external electric network when net-generation is negative, which may occur in maximum discharge dispatch strategy.

The indicator of net_use_rate is particularly needed in situations where maximum RES utilization is requested, situations where excess energy generated by RES should be curtailed if not stored by ESS, situations where real-time electricity price market is implemented and situations where the HES is isolated in remote areas.

2.4.3. BESS Use Rate. This indicator could reflect the use rate of BESS in different operation strategies, which is just a reference index. Used to evaluate the utilization rate of the BESS and only used for a reference evaluation indicator:

$$
\text { Vol_rate }=\frac{\sum_{k=1}^{T} \operatorname{Vol}_{b}(k)}{T \cdot \operatorname{Vol}_{b}} .
$$

The closer Vol_rate to 0.5 is, the higher utilization efficiency of the BESS is.

2.4.4. Peak Power at PCC. This indicator could reflect the ability of each control strategy in peak power shifting, which is an important reference index in deploying and upgrading transformer and other economic analysis situations:

$$
P_{\text {peak }}=\max \left(\left|P_{\text {grid }}(k)\right|, 0\right) \quad k=1,2, \ldots, T .
$$

\section{Mathematical Model of Strategies}

3.1. Normal Dispatch Strategy. This strategy describes the operation of HES with no EES, the operation of gridconnected HES just decided by current state of load demand, and RES generation. When HES has no ESS, the operation of it is very limited. Surplus energy should be delivered to the external grid when $Y(k)>0$; in the opposite case, insufficient energy will be purchased from the external grid when RES generation could not support local consumer. The performance of HES in this strategy is regarded as a benchmark for the other strategies:

$$
P_{\text {grid }}(k)=Y(k) \quad k=1,2, \ldots, T
$$

Subjected to: (3)-(4), (8).

3.2. Load following Dispatch Strategy. In this strategy, BESS will charge as much as possible unless reaching the BESS 
operation limits if BESS is not fully charged and $Y(k)$ is positive and then deliver surplus energy which could not be used locally into the external grid $[9,10]$. In the opposite case, BESS will discharge as much as possible unless reaching the operation limits if there is enough energy stored in BESS; the additional insufficient energy will be purchased from the external grid. Detailed mathematical model can be described as follows:

$$
\begin{aligned}
& P_{\text {grid }}(k)= \begin{cases}Y(k)-P_{b \max }, & P_{b \max } \leq Y(k), \mathrm{Vol}_{b}(k) \leq \mathrm{Vol}_{b \max } \\
Y(k), & 0 \leq Y(k), \mathrm{Vol}_{\text {max }} \leq \mathrm{Vol}_{b}(k) \\
Y(k)+P_{b \text { max }}, & Y(k) \leq-P_{b \max }, \mathrm{Vol}_{\text {min }} \leq \mathrm{Vol}_{b}(k) \\
Y(k), & Y(k) \leq 0, \mathrm{Vol}_{b}(k) \leq \mathrm{Vol}_{\text {min }} \\
0, & \text { otherwise, }\end{cases} \\
& P_{b}(k)= \begin{cases}P_{b \max }, & P_{b \max } \leq Y(k), \mathrm{Vol}_{b}(k) \leq \mathrm{Vol}_{b \max } \\
Y(t), & 0 \leq Y(k) \leq P_{b \max }, \mathrm{Vol}_{b}(k) \leq \operatorname{Vol}_{\text {max }} \\
Y(t), & -P_{b \max } \leq Y(k) \leq 0, \mathrm{Vol}_{\text {min }} \leq \mathrm{Vol}_{b}(k) \\
-P_{b \max }, & Y(k) \leq-P_{b \text { max },} \mathrm{Vol}_{\text {min }} \leq \operatorname{Vol}_{b}(k) \\
0, & \text { otherwise }\end{cases} \\
& k=1,2, \ldots, T \\
& \text { Subjected to: (3)-(8). }
\end{aligned}
$$

3.3. Maximum Charging Dispatch Strategy. Similar to the cycle charging strategy in [9], this strategy is suitable for situations where the frequency of $Y(k)>0$ is low [20]; namely, the penetration level of RES is not very high. If a HES has no ESS, the operation of it should be very limited.
The surplus energy must be delivered to the external grid or curtailed when $Y(k)>0$, in the opposite case, the insufficient energy has to be purchased from the external grid when $Y(k)<0$. Detailed mathematical model can be described as follows:

$$
\begin{aligned}
& P_{\text {grid }}(k)= \begin{cases}-P_{b \text { max }}+Y(k), & P_{b \max } \leq Y(k), \mathrm{Vol}_{b}(k) \leq \mathrm{Vol}_{b \max } \\
-P_{\text {grid }} \max , & P_{\text {grid }} \max +Y(k) \leq P_{b \max }, 0 \leq Y(k), \mathrm{Vol}_{b}(k) \leq \mathrm{Vol}_{\text {max }} \\
Y(k), & 0 \leq Y(k), \mathrm{Vol}_{\text {max }} \leq \mathrm{Vol}_{b}(k) \\
0, & -P_{b \max } \leq Y(k) \leq 0, \mathrm{Vol}_{\text {min }} \leq \mathrm{Vol}_{b}(k) \\
Y(k)+P_{b \text { max }} & Y(k) \leq-P_{b \text { max }}, \mathrm{Vol}_{\text {min }} \leq \mathrm{Vol}_{b}(k) \\
Y(k) & \mathrm{Vol}_{b}(k) \leq \mathrm{Vol}_{\text {min }}\end{cases} \\
& P_{b}(k)= \begin{cases}P_{b \text { max }}, & P_{b \text { max }} \leq P_{\text {grid }} \max +Y(k), \mathrm{Vol}_{b}(k) \leq \mathrm{Vol}_{\text {max }} \\
P_{\text {grid }} \max +Y(k), & 0 \leq P_{\text {grid }} \max +Y(k) \leq P_{b \text { max }}, \mathrm{Vol}_{b}(k) \leq \mathrm{Vol}_{\text {max }} \\
Y(k), & -P_{b \text { max }} \leq Y(k) \leq 0, \mathrm{Vol}_{\text {min }} \leq \mathrm{Vol}_{b}(k) \\
-P_{b \text { max }}, & Y(k) \leq-P_{b \text { max }}, \mathrm{Vol}_{\text {min }} \leq \mathrm{Vol}_{b}(k) \\
0, & \text { otherwise }\end{cases}
\end{aligned}
$$

$$
k=1,2, \ldots, T
$$

Subjected to: (3)-(8). 
3.4. Maximum Discharging Dispatch Strategy. This strategy is suitable for situations where the frequency of $Y(k)>0$ is lower than that of maximum charging dispatch strategy; thus the penetration level of RES is lower than maximum charging strategy, which is similar to the strategy of peak shaving of [9]. The operation of BESS is the same as load following dispatch strategy when $Y(k)>0$; in the opposite case, if BESS could meet the demand of insufficient power of RES, BESS will discharge as much as needed; otherwise, the external grid will export power to HES, meet the insufficient power of RES, and charge the BESS at the same time, if not exceeding the constraints described in Section 2.3:

$$
\begin{aligned}
& P_{\text {grid }}(k)= \begin{cases}Y(k)-E_{b \text { max }}, & P_{b \text { max }} \leq Y(k), \mathrm{Vol}_{b}(k) \leq \mathrm{Vol}_{b \text { max }} \\
Y(k), & 0 \leq Y(k), \mathrm{Vol}_{\text {max }} \leq \operatorname{Vol}_{b}(k) \\
P_{\text {grid }} \text { max }, & Y(k) \leq-\left(P_{\text {grid }} \max +P_{b \text { max }}\right) \leq 0, \mathrm{Vol}_{\text {min }} \leq \mathrm{Vol}_{b}(k) \\
P_{\text {grid }} \max , & \left(\operatorname{Vol}_{b}(k) \leq \operatorname{Vol}_{b \text { max }}, P_{\text {grid }} \max +Y(k) \leq P_{b \text { max }}-\left(P_{\text {grid }} \max +P_{b \text { max }}\right) \leq Y(k) \leq 0\right) \\
-Y(k)+P_{b \text { max }}, & \left(\operatorname{Vol}_{b}(k) \leq \operatorname{Vol}_{b \text { max }}, P_{b \text { max }} \leq P_{\text {grid }} \max +Y(k)-\left(P_{\text {grid }} \max +P_{b \text { max }}\right) \leq Y(k) \leq 0\right) \\
Y(k), & Y(k) \leq 0, \operatorname{Vol}_{b}(k) \leq \operatorname{Vol}_{\text {min }} \\
0, & \text { otherwise, }\end{cases} \\
& P_{b}(k)= \begin{cases}P_{b \text { max }}, & P_{b \text { max }} \leq Y(k), \mathrm{Vol}_{b}(k) \leq \mathrm{Vol}_{b \text { max }} \\
Y(k), & 0 \leq Y(k) \leq P_{b \text { max }}, \operatorname{Vol}_{b}(k) \leq \operatorname{Vol}_{\text {max }} \\
Y(k), & -P_{b \text { max }} \leq Y(k) \leq 0, \operatorname{Vol}_{\text {min }} \leq \operatorname{Vol}_{b}(k) \\
-P_{\text {grid }} \max , & Y(k) \leq-\left(P_{\text {grid }} \max +P_{b \text { max }}\right) \leq 0, \operatorname{Vol}_{\text {min }} \leq \operatorname{Vol}_{b}(k) \\
P_{\text {grid }} \max +Y(k), & \left(\operatorname{Vol}_{b}(k) \leq \operatorname{Vol}_{b \text { max }}, P_{\text {grid }} \max +Y(k) \leq P_{b \text { max }}-\left(P_{\text {grid }} \max +P_{b \text { max }}\right) \leq Y(k) \leq 0\right) \\
P_{b \text { max }}, & \left(\operatorname{Vol}_{b}(k) \leq \operatorname{Vol}_{b \text { max }}, P_{b \text { max }} \leq P_{\text {grid }} \max +Y(k)-\left(P_{\text {grid }} \max +P_{b \text { max }}\right) \leq Y(k) \leq 0\right) \\
0, & \text { otherwise }\end{cases} \\
& k=1,2, \ldots, T
\end{aligned}
$$

Subjected to: (3)-(8).

3.5. Multistage Dispatch Strategy. Many new infrastructures and technologies are put into power system from electricity generation, transmission, and distribution to consuming, for integrating more RES and making grid system smarter. By taking advantage of the advanced communication network, rich data and information could be sent to and received from each component of the HES in a timely fashion. Researches results showed that short time RES generation output, load demand, and electricity price could be modeled effectively by autoregressive (AR) [21] processes, machine learning [22], or other methods [23]. These technology progress and researches are worthy for alleviating fluctuation and fully using RES in HES when the penetration level of RES is high. However, communication network and forecasting methods are not the focus of this paper; relational information could be found in [24] and the references therein.

As the literal meaning, the multistage dispatch strategy proposed in this paper consists of two main stages. First, preoptimize the BESS charge and discharge plan with considering the forecast data of RES generation and load demand day-ahead by modified dynamic programming algorithm [25]. The objective is to mitigate the fluctuation of the forecast power flowed in HES as much as possible. Then, refer to hysteresis control method in [15] and heuristic dispatch algorithm in [26]; a dynamic robust adjust control method is implemented based on scheduled BESS operation routine and real-time data of the HES. Detailed multistage dispatch strategy could be described as follows.

Stage 1: Preoptimize the Operation of BESS with Day-Ahead Forecast Data Using Modified Dynamic Programming Algorithm

(1) Obtain the day-ahead predicted data of load demand, RES generation (wind and PV).

(2) Compute the whole day net-generation of HES by formula (17).

(3) Solve the preoptimization problem with modified dynamic programming algorithm, which can be formulated as follows.

Objective. Minimize the standard variance of power flowed at PCC (net-generation) with predicted data:

$$
\begin{gathered}
\min \cdot \frac{1}{N} \sum_{k=1}^{N}\left[Y_{\text {pre }}(k)-P_{b \text { pre }}(k)-\frac{1}{N} \sum_{i=1}^{N}\left(Y_{\text {pre }}(k)-P_{b \text { pre }}(k)\right)\right]_{(16)}^{2} \\
Y_{\text {pre }}(k)=P_{\text {prewind }}(k)+P_{\text {presolar }}(k)-P_{\text {preload }}(k) \\
\text { Subjected to: }(3)-(8),
\end{gathered}
$$


where the formula of (16) is a mix-integer nonlinear programming problem; conventional algorithm could not search the optimal solution easily; however, modified dynamic programming could solve this problem effectively and quickly:

$$
\begin{gathered}
f_{i+1}\left(\operatorname{Vol}_{\text {pre }}(i+1)\right) \\
=\min \left\{f_{i}\left(\operatorname{Vol}_{\text {pre }}(i)\right), v\left(\operatorname{Vol}_{\text {pre }}(i), P_{b \text { pre }}(i)\right)\right\} \\
\operatorname{Vol}_{\text {pre }}(i+1)=\operatorname{Vol}_{\text {pre }}(i)+P_{b \text { pre }}(i) \cdot \Delta t \\
f_{0}\left(\operatorname{Vol}_{\text {pre }}(0)\right)=0 \\
i=0,1, \ldots, N-1
\end{gathered}
$$

Subjected to: (3)-(8),

where $f_{i+1}\left(\operatorname{Vol}_{\text {pre }}(i+1)\right)$ refers to the standard variance of power flowed at PCC in period $i+1$ with standard variance $f_{i}\left(\operatorname{Vol}_{\text {pre }}(i)\right)$ in period $i$; $v\left(\operatorname{Vol}_{\text {pre }}(i), P_{b \text { pre }}(i)\right)$ denotes the index function [27].

Stage 2: Heuristic Dispatch Control Combined with Hysteresis Band Based on Real-Time Data. Predicted data of load demand and RES generation (PV and wind) could not be so perfect because of forecast uncertainty, which lead to the fact that real-time operation of HES could not follow the preplanned routine completely; BESS should fully play its unique role as it could be operated as a load or generator unit if needed to alleviate fluctuations and improve power quality of HES in real-time as much as possible. For reaching this aim, a real-time robust control algorithm, namely, heuristic dispatch control combined with hysteresis band, is proposed. Detailed procedures can be described as follows.

(4) Collect the real-time data of load demand and RES generation ( $\mathrm{PV}$ and wind) in period $k$.

(5) Compare the actual net-generation $Y(k)$ and the forecasted net-generation $Y_{\text {pre }}(k)$ and then compute the actual forecast error level in period $k$ :

$$
\begin{gathered}
\operatorname{temp}(k)=Y(k)-Y_{\text {pre }}(k) \quad k=1,2, \ldots, N \\
L_{\text {error }}(k)=\frac{\operatorname{temp}(k)}{Y_{\text {pre }}(k)}
\end{gathered}
$$

where if the equation of (19) combined with the forecast error of RES generation (PV and wind) and load demand, in this way, much computational room and time could be saved. $L_{\text {error }}(k)$ is an important variable in deciding BESS realtime control operation [21], and we assume that $-E_{P, \max } \leq$ $L_{\text {error }}(k) \leq E_{P \text {, max }}$; if $L_{\text {error }}(k)$ exceed this scope, we define that $L_{\text {error }}(k)$ equals the closest value in this scope.

(6) Determine the size of hysteresis band.

According to the past experiences of our work and other researchers [28], there are many periods that $\operatorname{temp}(k)$ are very small values close to zero; in these conditions, BESS will operate as scheduled day-ahead as much as possible. The size of hysteresis band in this paper was computed with a modified method from $[15,27]$ :

$$
\Delta E_{\mathrm{HES}}=2 \cdot C_{\mathrm{HES}} \cdot P_{b \max },
$$

where $0<C_{\mathrm{HES}}<1$ is an important factor used to determine the size of hysteresis band and the value of $C_{\mathrm{HES}}$ has close relationship with BESS characteristics, load characteristics, and forecast uncertainty levels.

Hysteresis band can be used to decide when the BESS charge or discharge power and also could extend the cycle life of BESS; however, because of forecast uncertainty, how much BESS should be charged or discharged in power fluctuation smoothing also should be determined.

(7) Implement heuristic dispatch control policy combined with hysteresis band to mitigate fluctuation in HES at real-time.

Real-time operation of BESS should consider the forecast error of load demand and RES generation, the capacity level of BESS, and the total power level of this day; conventional control strategies could not deal with this problem effectively; however, the heuristic dispatch policy combined with hysteresis band proposed in this paper could solve this problem:

$$
\begin{aligned}
& \operatorname{level}(k)= \begin{cases}\frac{Y(k)}{Y_{\text {premin }}}, & \text { if } Y(k)<0 \\
\frac{Y(k)}{Y_{\text {premax }}}, & \text { otherwise }\end{cases} \\
& P_{b}(k)=f\left(\operatorname{Vol}_{b}(k), L_{\text {error }}(k), \text { level }(k)\right)+P_{b \text { pre }}(k) \\
& k=1,2, \ldots, N
\end{aligned}
$$

Subjected to: (3)-(8),

where level $(k)$ is an auxiliary variable and represents the netgeneration level of period $k$ in one day, which is important for actual BESS operation. $f$ is a function of BESS capacity, forecast error, net-generation level, and scheduled power of BESS at period $k$ in day-ahead programming. The detailed BESS heuristic dispatch control policy combined hysteresis band of real-time operation can be demonstrated as the following the steps.

(7.1) Collect the value of level $(k)$, if level $(k)>1$; adjust the BESS operation to satisfy the power scheduled as much as possible, if not over the limit of BESS. Otherwise, it proceeds to (7.2).

(7.2) If the actual net-generation power is in the hysteresis band, $\mid$ temp $(k) \mid<\Delta E_{\mathrm{HES}}$, and BESS were operated as scheduled; if temp $(k)>0$, excess energy will be exported to the external grid; on the contrary, purchase the demand deficit from the external grid. Otherwise, it proceeds to (7.3).

(7.3) The operation power of BESS in period $k$ can be represented as follows:

$$
P_{b}(k)=f\left(\operatorname{Vol}_{b}(k), L_{\text {error }}(k)\right),
$$




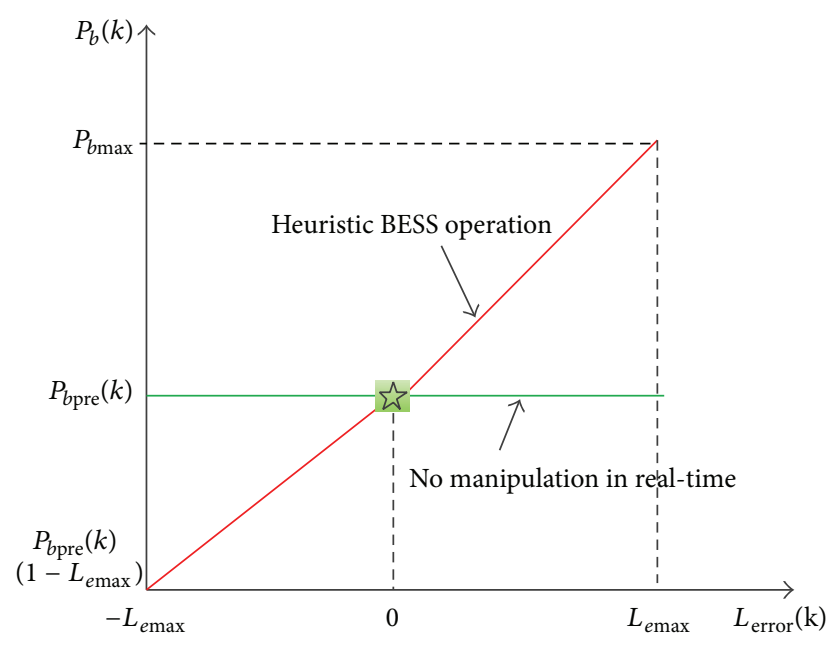

FIGURE 2: Real-time BESS operation with heuristic dispatch strategy.

where $P_{b}(k)$ is varying with respect to $f$; for easy understanding, we do not use complex function to show the relationships among $P_{b}(k)$ with $\operatorname{Vol}_{b}(k)$ and $L_{\text {error }}(k)$, just as formula (23) and Figure 2 illustrated. In Figure 2, the green line means that HES controller actually operates the BESS at real-time just with forecast data directly as the control without any manipulation, whereas the red line means that the BESS capacity and actual net-generation in period $k$ are concerned; BESS actual operation should consider the current state of the system. The detailed illustration of heuristic algorithm is presented in $[29,30]$ and their reference articles:

$$
P_{b}(k)=\left\{\begin{array}{r}
P_{b \text { pre }}(k)\left(1+L_{\text {error }}(k)\right), \\
\text { if } L_{\text {error }}(k)<0 \\
P_{b \text { pre }}(k)+\left(P_{b \max }-P_{b \text { pre }}(k)\right)\left(\frac{L_{\text {error }}(k)}{E_{P, \max }}\right), \\
\text { if } Y(k)>0, L_{\text {error }}(k)>0 \\
P_{b \text { pre }}(k)-\left(P_{b \text { pre }}(k)-P_{b \max }\right)\left(\frac{L_{\text {error }}(k)}{E_{P, \max }}\right), \\
\text { if } Y(k)<0, L_{\text {error }}(k)>0 \\
k=1,2, \ldots, N
\end{array}\right.
$$

Subjected to: (3)-(8).

(8) Update the BESS state, move to the time step of $k+1$, and repeat the algorithm from step (4) if this day is not over; otherwise go to step (1) until the end of the whole simulation horizon.

This two-stage dispatch strategy also has other benefits to HES such as cost saving and system reliability improving; however, not being the focus of this paper, there is no cover about them.

\section{Simulation and Results}

For better demonstrating the performance of each BESS operation strategy, this section is divided into four successive parts. One-day case study of each BESS operation strategy in power fluctuation smoothing is implemented in Section 4.1; a vivid impression will be about the performance of each strategy; Section 4.2 describes the performance of each BESS dispatch strategy of one whole simulation horizon, which is based on the analysis of one-day case, but the conclusions are more convincing and more detailed than Section 4.1; sensitive analysis of each BESS dispatch strategy in situations where BESS parameters are fixed but the forecasts results are imperfect is presented in Section 4.3; Section 4.4 analyzes the performance changes in situations where forecast uncertainty is fixed but the BESS parameters are varying. The former two parts could be considered as special cases of the latter two parts; they analyze the power fluctuation performance of each BESS strategy in HES with high RES penetration level in perfect forecast conditions; however, the latter two parts discuss the robust feature of each BESS dispatch strategy in conditions where forecast results are imperfect or BESS parameters are varying. The data needed in this paper is coming from [31].

Figure 3 shows the power of actual PV generation, wind generation, load demand, and net-generation of HES of this paper in the whole simulation horizon, respectively. The red line represents the power of PV generation, the blue line shows the power of wind generation, the green line indicates the load demand, and the cyan line denotes net-generation of HES, respectively.

Figure 3 fully illustrates the properties of RES generation and load demand from the point of one whole year. By comparison of red line of PV generation and blue line of wind generation, we could observe that both of them have the feature of intensive fluctuation, intermittency, and seasonal changing. In general, sunlight in summer is richer than in winter; however, wind source is richer in winter than in summer; therefore, this phenomenon shows that a HES has more advantages than energy systems which only have one kind of them. Furthermore, we could also observe that the stochastic feature of wind generation is more significant than that of PV generation and load demand. The feature of load demand is that more energy is needed in winter than in summer, just because winter needs more electricity energy to be used to keep houses warm.

All the parameters needed in this paper are shown as follows: $\alpha=90 \%, \beta=10 \%, \mathrm{Vol}_{b}=2400 \mathrm{kWh}, P_{b \max }=$ $800 \mathrm{~kW}$, and $C_{\mathrm{HES}}=0.05$, and the initial BESS capacity is $\operatorname{Vol}_{b}(0)=(1 / 2) \operatorname{Vol}_{b}, N=96, M=365$; for simplicity, we assume that the rated power of transformer between the grid-connected HES and the external grid could support the load demand if no RES generators exist; namely, $P_{\text {grid }} \max =$ $\max (-\min (Y(t)), \max (Y(t)))$.

4.1. One-Day Case Simulation. In Figure 4, the green lines intuitively show the performance of BESS in mitigating fluctuation in different strategies of one typical day. Where multistage dispatch strategy has the best performance because 


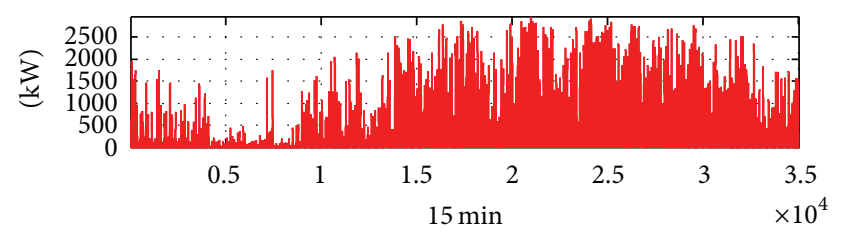

— PV power

(a) PV generation

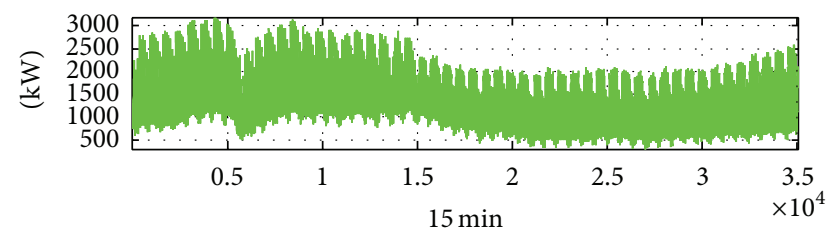

Load demand

(c) Load demand

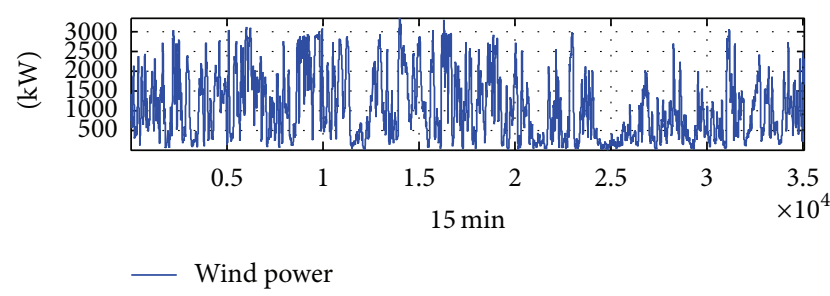

(b) Wind generation

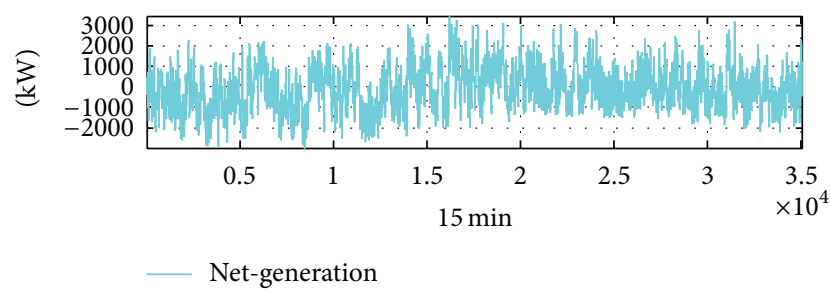

(d) Net-generation

FIGURE 3: Data of RES generation and load demand for HES in one year.

BESS could effectively and intelligently shift the peak power to smooth the net-generation power flowed at PCC in this strategy, however, the other strategies could not achieve this purpose, because they all rule based strategy; the BESS operation in these strategies just follows the real-time netgeneration. They do not have preoptimization of BESS nor real-time robust adjustment actions for compensating the errors of day-ahead prediction; therefore, their performances in alleviating power fluctuation are very limited. By observing the cyan lines we could find that the operation of BESS in strategy of multistage dispatch is more flexible and intelligent.

Table 1 reports the performances of the described strategies as Figure 3 shows. It demonstrates that the benchmark value standard variance is 680.224, different BESS operation strategies have different performances, and the differences are very significant, in these strategies. The performances of maximum charging strategy and maximum discharging strategy have close relationship with tendency of netgeneration power flowed in HES and RES penetration level; in this one day case, the power curve is not idea for maximum charging and maximum discharging dispatch strategy, and the size of BESS is too small for these strategies to fully take their advantages. The reason why the value of index net_use_rate seems tiny is that this value is decided by the definition of net_use_rate in Section 2, and the fact that BESS size is not so idea is another one important reason. Other evaluation indicators have no meaning presented in one-day case simulation, which will be shown in the next further analysis.

Figure 4 and Table 1 just show the performance of all the strategies in alleviating power fluctuation and improving power in HES of one typical day. We could not obtain the final conclusion that which BESS operation strategy has the best performance just trough these simple simulation results, hence, further researches of longer time simulation (at least one year) in different forecast uncertainty levels, and different size of BESS should be discussed.

4.2. Whole Horizon Duration Study (One Year). The results shown in Table 2 demonstrate the performance of power fluctuation smoothing and quality improvement of each strategy of one year. In total, the HES power quality and operation improvement through BESS integration are very effective. For example, the standard variance of power flowed in HES at PCC reduced more or less for multistage dispatch, load following, and maximum charging dispatch strategy; furthermore, the indicator net_use_rate demonstrates that all the BESS strategies increase the use rate of RES in local HES, which has significant benefits when RES penetration level increased.

In all of the BESS operation strategies referred to in this paper, only multistage dispatch strategy reduces the peak power of HES, which demonstrates the superiority and intelligence of this strategy; despite the fact that there are many reasons leading to this result, such as BESS capacity, the occasion of peak power coming forth, only multistage dispatch could grasp opportunities effectively. The reason that the standard variance of power flowed in HES for maximum discharging dispatch strategy is higher than benchmark is that when RES generation and BESS discharging could not meet load demand, and the external grid will import power to support load demand and charge the BESS at the same time, which result in more subpeak power demand.

The indicator of Vol_rate demonstrates that BESS could fully develop the unique feature in all strategies and, namely, could be regarded as a load or a generator in different conditions when needed; in addition to maximum discharging strategy, in this strategy, BESS capacity stay at high level in most periods.

Although many helpful results and conclusions could be obtained, however, all the results of Figure 3 and Tables 1 
TABle 1: Performance of different strategies in mitigating power fluctuation and improving power quality (one typical day case).

\begin{tabular}{lccccc}
\hline Evaluation index & Normal strategy & $\begin{array}{c}\text { Multistage dispatch } \\
\text { strategy }\end{array}$ & $\begin{array}{c}\text { Dispatch strategy } \\
\text { Load following } \\
\text { strategy }\end{array}$ & $\begin{array}{c}\text { Maximum charging } \\
\text { strategy }\end{array}$ & $\begin{array}{c}\text { Maximum } \\
\text { discharging strategy }\end{array}$ \\
\hline Var & 680.224 & 442.444 & 529.156 & 587.563 & 682.340 \\
\hline net_use_rate & - & 0.212 & 0.164 & 0.137 & 0.141 \\
\hline
\end{tabular}

TABLE 2: Performance of different strategies in mitigating power fluctuation and improving power quality (a whole year).

\begin{tabular}{lccccc}
\hline Evaluation index & Normal strategy & $\begin{array}{c}\text { Multistage dispatch } \\
\text { strategy }\end{array}$ & $\begin{array}{c}\text { Dispatch strategy } \\
\text { Load following } \\
\text { strategy }\end{array}$ & $\begin{array}{c}\text { Maximum charging } \\
\text { strategy }\end{array}$ & $\begin{array}{c}\text { Maximum } \\
\text { discharging strategy }\end{array}$ \\
\hline Var & 713.281 & 492.111 & 622.933 & 658.319 & 783.686 \\
\hline net_use_rate & - & 0.1562 & 0.1572 & 0.103 & 0.1107 \\
\hline Vol_rate & - & 0.5250 & 0.4556 & 0.5058 & 0.7591 \\
\hline$P_{\text {peak }}(\mathrm{kW})$ & 4170.6 & 3430.6 & 4170.6 & 4170.6 & 4170.6 \\
\hline
\end{tabular}

TABLE 3: Performance of each BESS dispatch strategy in different forecast uncertainty levels of one-year simulation.

\begin{tabular}{|c|c|c|c|c|}
\hline & Var & net_use_rate & (Vol_rate) & $P_{\text {peak }}(\mathrm{kW})$ \\
\hline \multirow{5}{*}{$\begin{array}{l}\text { Sensitive test } 1 \\
\left(E_{P, \max }=5 \%\right)\end{array}$} & Normal: 726.611 & Normal: — & Normal: — & Normal: 4541.1 \\
\hline & Strategy 1: 506.055 & Strategy 1: 0.1556 & Strategy 1: 0.5186 & Strategy 1: 3778.74 \\
\hline & Strategy 2: 640.295 & Strategy 2: 0.1566 & Strategy 2: 0.4523 & Strategy 2: 4541.1 \\
\hline & Strategy 3: 670.277 & Strategy 3: 0.0818 & Strategy 3: 0.5160 & Strategy 3: 4541.1 \\
\hline & Strategy 4: 798.987 & Strategy 4: 0.1041 & Strategy 4: 0.7595 & Strategy 4: 4541.1 \\
\hline \multirow{5}{*}{$\begin{array}{l}\text { Sensitive test } 2 \\
\left(E_{P, \max }=10 \%\right)\end{array}$} & Nor: 744.851 & Normal: - & Normal: - & Normal: 5254.9 \\
\hline & Strategy 1: 517.445 & Strategy 1: 0.1548 & Strategy 1: 0.5192 & Strategy 1: 4546.2 \\
\hline & Strategy 2: 648.471 & Strategy 2: 0.1557 & Strategy 2: 0.4536 & Strategy 2: 5254.9 \\
\hline & Strategy 3: 678.594 & Strategy 3: 0.0816 & Strategy 3: 0.5160 & Strategy 3: 5254.9 \\
\hline & Strategy 4: 808.7514 & Strategy 4: 0.1027 & Strategy 4: 0.7628 & Strategy 4: 5254.9 \\
\hline \multirow{5}{*}{$\begin{array}{l}\text { Sensitive test } \\
3\left(E_{P, \max }=15 \%\right)\end{array}$} & Normal: 759.056 & Normal: - & Normal: - & Normal: 5459.0 \\
\hline & Strategy 1: 542.540 & Strategy 1: 0.1534 & Strategy 1: 0.5198 & Strategy 1: 4824.8 \\
\hline & Strategy 2: 662.520 & Strategy 2: 0.1553 & Strategy 2: 0.4542 & Strategy $2: 5459.0$ \\
\hline & Strategy 3: 692.914 & Strategy 3: 0.0808 & Strategy 3: 0.5149 & Strategy 3: 5459.0 \\
\hline & Strategy 4: 831.333 & Strategy 4: 0.0983 & Strategy 4: 0.7675 & Strategy 4: 5459.0 \\
\hline \multirow{5}{*}{$\begin{array}{l}\text { Sensitive test } 4 \\
\left(E_{P, \max }=20 \%\right)\end{array}$} & Normal: 784.327 & Normal: - & Normal: - & Normal: 8416.9 \\
\hline & Strategy 1: 583.307 & Strategy 1: 0.1515 & Strategy 1: 0.5174 & Strategy 1: 7692.5 \\
\hline & Strategy 2: 692.956 & Strategy 2: 0.1548 & Strategy 2: 0.4523 & Strategy 2: 8416.9 \\
\hline & Strategy 3: 723.663 & Strategy 3: 0.0796 & Strategy 3: 0.5187 & Strategy 3: 8416.9 \\
\hline & Strategy $4: 865.802$ & Strategy 4: 0.0978 & Strategy 4: 0.7704 & Strategy 4: 8416.9 \\
\hline
\end{tabular}

and 2 are based on fixed parameters of BESS and forecast uncertainty level; the conclusions obtained could not be convincing if we need to use these conclusions to determine BESS size and conduct actual BESS operation; therefore, further discussions should be implemented to demonstrate the performances of different strategies in different conditions.

4.3. Sensitive Analysis 1. This subsection discusses the performance degrading of each BESS strategy in different forecast uncertainty conditions, with fixed BESS size. For easy understanding, we just use the variation of net-generation to represent the variation of RES generation (wind, PV) and load demand; thus, the real-time net-generation could be formulated as follows:

$$
\begin{array}{r}
Y(k)=Y_{\text {pre }}(k) \cdot\left(1+E_{P, \max } \cdot R_{P}\right) \\
k=1,2, \ldots, N
\end{array}
$$

where the mean value of $R_{P}$ is 0 and the standard variance is 1 ; in this paper, we just set four forecast uncertainty levels, and $E_{P, \max }$ is $5 \%, 10 \%, 15 \%$, and $20 \%$, respectively.

For saving space, we use short nomenclature normal; Strategy 1, Strategy 2, Strategy 3, and Strategy 4 replace normal operation strategy, multistage dispatch strategy, load following dispatch strategy, maximum charging dispatch strategy, and maximum discharging dispatch strategy, respectively.

The results shown in Table 3 and Figure 4 demonstrate the performance of each operation strategy in mitigating fluctuation and improving power quality of HES with high penetration level of RES integration under conditions that the forecast is imperfect. This sensitive analysis is mainly used for evaluating the robust of each BESS dispatch strategy in conditions that the BESS sizes in HES have been decided but 


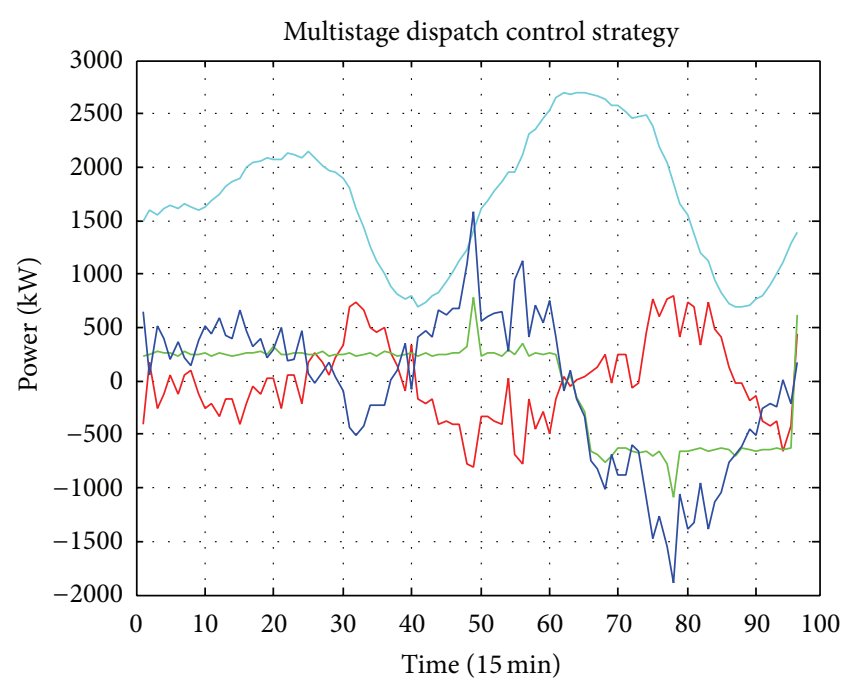

(a)

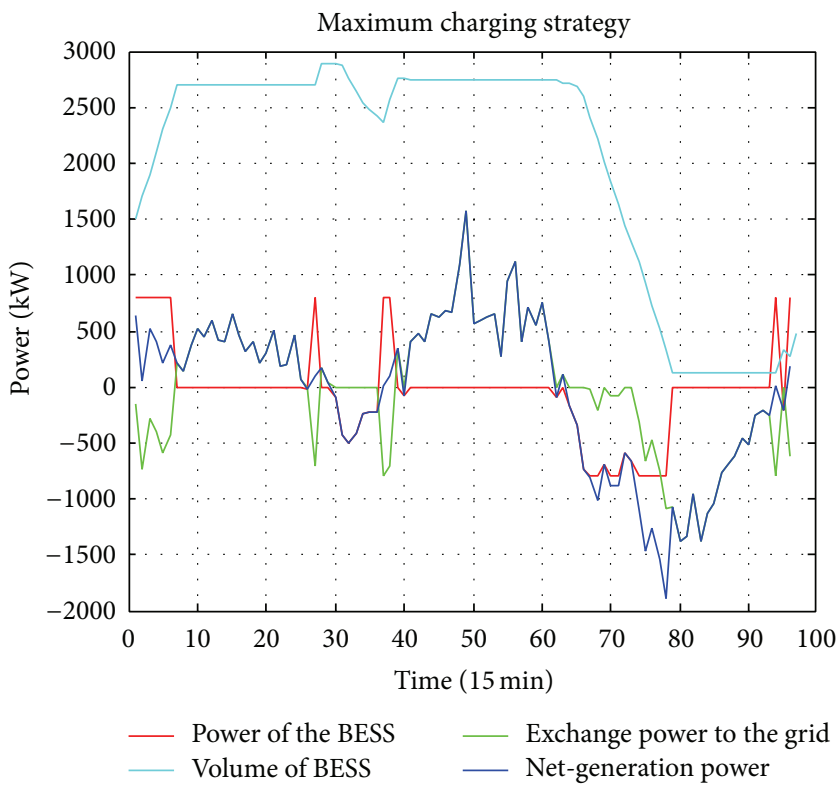

(c)

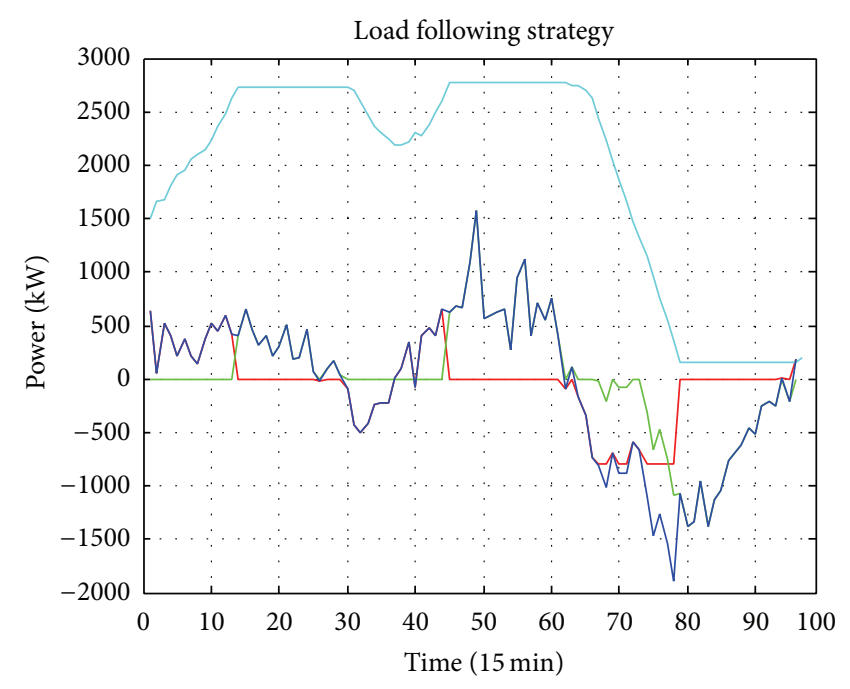

(b)

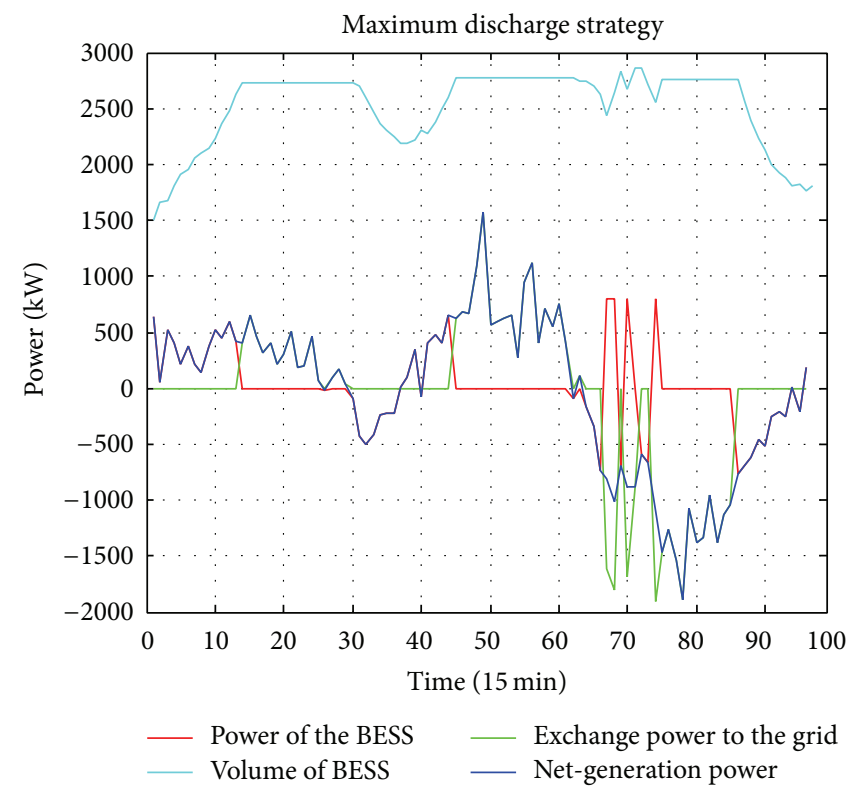

(d)

FIGURE 4: Performance of different strategies in mitigating fluctuation and improving power quality. (a) Multistage dispatch strategy. (b) Load following dispatch strategy. (c) Maximum charging dispatch strategy. (d) Maximum discharging dispatch strategy (one typical day case).

actual RES generation (wind, PV) and load demand are not as assumed in planning.

Observing the indicator of Var in Table 3 and Figure 5, we could find that the performance of multistage dispatch strategy is more robust than other strategies, as the tendencies of five lines in Figure 4 show, the tendencies of the other strategies follow the tendency of normal strategy without BESS, and their performances all have closer relationship with the forecast uncertainty than multistage dispatch strategy. Observing the indicator of net_use_rate, we could find that the performances of maximum charging strategy and maximum discharging dispatch strategy degrade rapidly with forecast uncertainty level increasing; however, the performance of multistage dispatch strategy and load following strategy keep steady very well. Observing the indictor of Vol_rate and $\mathrm{P}_{\text {peak }}$ could obtain the similar conclusions like net_use_rate.

4.4. Sensitive Analysis 2. As discussed above in this paper, BESS size level plays a very important role in power fluctuation smoothing and quality improving for HES which integrated with high penetration level of RES; suitable BESS size will help to fully develop the performance of dispatch strategy. In this subsection, we will investigate the relationships between BESS size and BESS operation performance.

Because the strategy of normal operation without BESS has no BESS integration, the investigations and results will not be referred to; in addition to this strategy, all other 


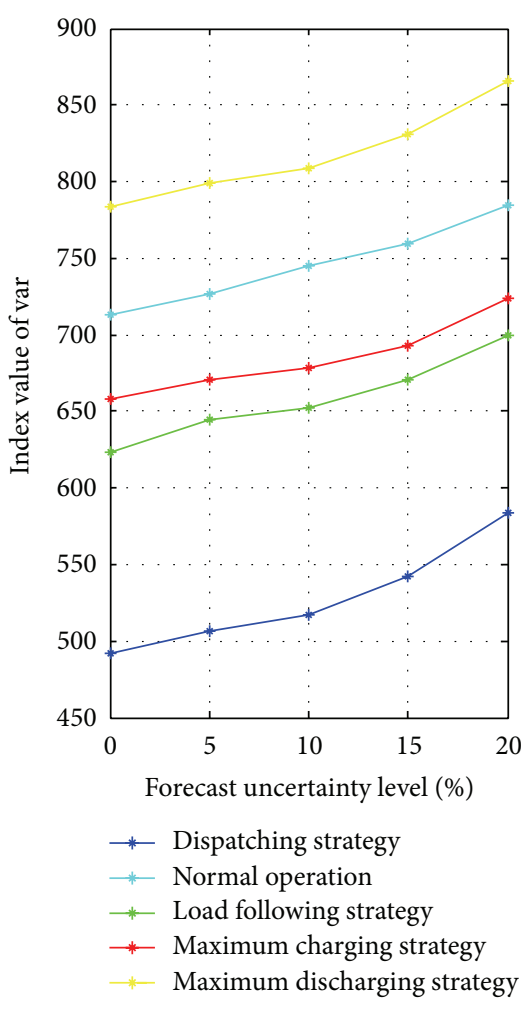

(a)

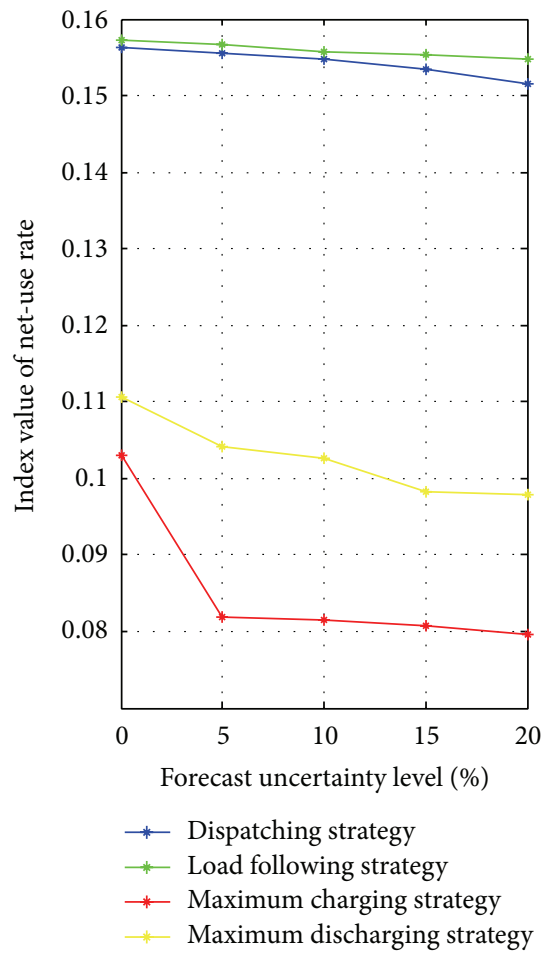

(b)

FIGURE 5: Performance of each BESS dispatch strategy with different forecast uncertainty levels in one year simulation. (a) Standard variance. (b) Net RES use rate.

strategies will be discussed from the indicator of standard variance, net RES use in HES, and mean BESS utilization rate. When we did experiments, we found that the tendency of BESS performance in multistage strategy is very evident; therefore, the BESS parameters range in this strategy is not so large, and the limited power ranges from $500 \mathrm{kw}$ to $3000 \mathrm{kw}$, and the limited capacity ranges from $1000 \mathrm{kwh}$ to $9000 \mathrm{kwh}$. For the other strategies, the limited power ranges from $500 \mathrm{kw}$ to $15500 \mathrm{kw}$, and the limited capacity ranges from $500 \mathrm{kwh}$ to $15500 \mathrm{kwh}$. In addition to that, we assume that the forecast uncertainty level in this subsection is $5 \%$ in all strategies.

Figure 6(a) demonstrates that with the increasing of BESS capacity the standard variance of power flowed in HES decreases, but if power of BESS could not increase with the increasing of capacity, the increasing rate of standard variance will be slower and slower; however, the power increasing rate should not keep with the increasing rate of capacity, and the trend could be observed from the graph. Figure 6(b) illustrates the similar trends like Figure 6(a), as the increasing of BESS capacity and power, the RES using rate through the charging and discharging of BESS in HES increasing steady. Figure 6(c) presents that with the increasing of BESS capacity and power, the use rate of BESS increases in the beginning and then keeps steady when the capacity and power of BESS are enough and then keeps decreasing when the capacity and power are too large to HES.

After carefully observing Figure 7 and comparing with Figure 6, we could obtain the following conclusions. The total trend of performance improving with the increasing of BESS limited capacity and power is similar like analyzed in Figure 7; however, the performance improving rate is slower than multistage dispatch strategy, such as when $P_{b \max }=$ $15500 \mathrm{~kW}, \mathrm{Vol}_{b}=15500 \mathrm{kWh}$, the $\mathrm{Var}=480.5563$, and net_use_rate $=0.3804$ (there is a little distortion in graph compression); this performance has been reached when $\mathrm{Vol}_{b} \leq 5000 \mathrm{kwh}$ to the strategy of multistage dispatch.

Comparing with Figures 6 and 8, there are some differences with the other two strategies which have been analyzed. First, the total tendency of performance in power smoothing has some difference with the strategy of multistage dispatch and load following. The performance in power fluctuation smoothing is improving with the BESS capacity and power increase, no possibility to grow worse at least; however, in strategy of maximum charging, this tendency is not suitable, and if the rated capacity is fixed, the performance will degrade with the increasing of rated power; the optimal standard variance is Var $=553.797$, where $P_{b \max }=1000 \mathrm{~kW}$ and $\mathrm{Vol}_{b}=10500 \mathrm{kWh}$. Second, with the increasing of BESS capacity, the net-use rate of RES will be growing, but slower and slower, and the highest value is net_use_rate = 0.2386 , which is too small to be compared with the above two strategies; furthermore, the net-use rate of RES will be decreasing sharply with the increasing of rated power of BESS. The last but not least, the use rate of BESS varies a lot with the varying of BESS rated power and capacity. Figure 8 demonstrates the importance of deciding suitable 


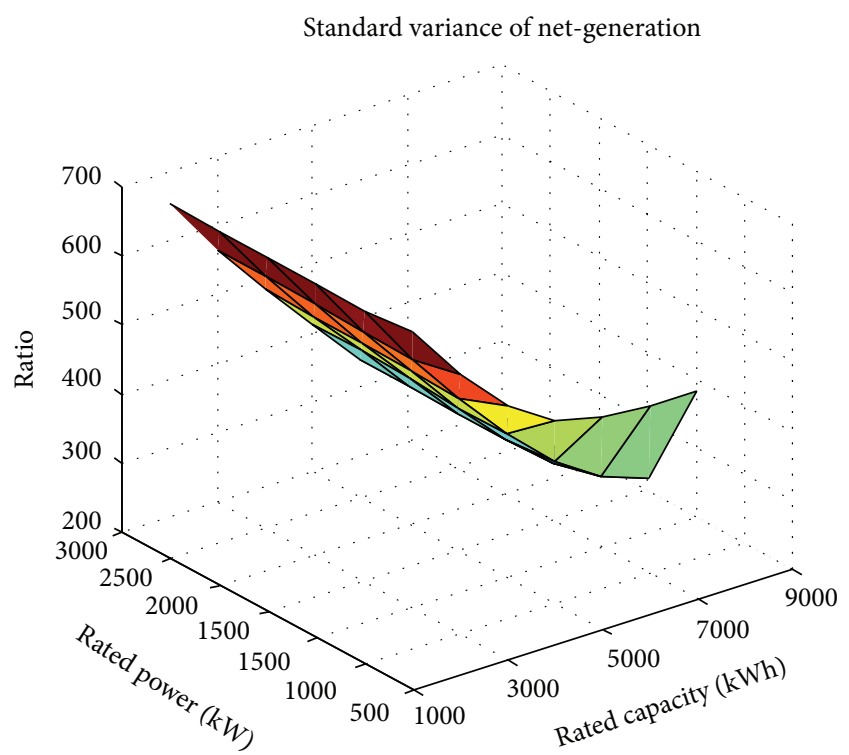

(a)

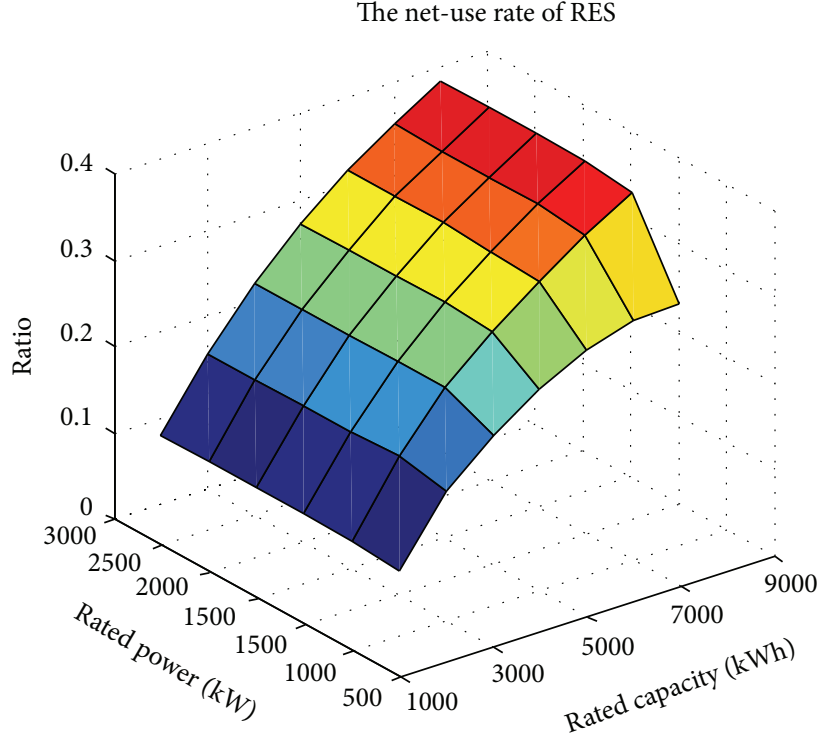

(b)

The use rate of BESS

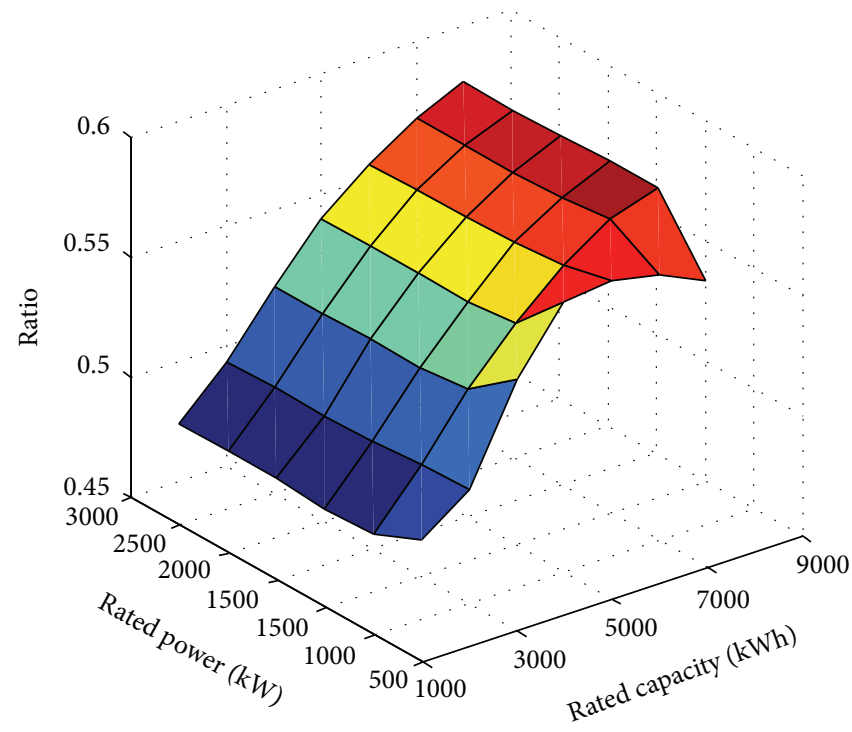

(c)

FIGURE 6: Performance of multistage dispatch strategy with different levels of BESS parameters. (a) Standard variance of net-generation at PCC. (b) Net-use rate of RES in HES. (c) BESS use rate.

and effective parameter of BESS no matter which operation strategy.

The performance of maximum discharging strategy also has some unique characteristics comparing with multistage dispatch strategy, load following strategy, and maximum charging strategy. The optimal standard variance is $\mathrm{Var}=$ 734.019 , where $P_{b \max }=500 \mathrm{~kW}$ and $\mathrm{Vol}_{b}=11000 \mathrm{kWh}$, as Figure 9(a) shows. The optimal value of var is not obtained when $\mathrm{Vol}_{b}=15500 \mathrm{kWh}$, which illustrates that the performance of power fluctuation smoothing do not improve with the increasing of BESS capacity like other strategies. As Figure 9(b) demonstrates, the trends of net-use rate of
RES are similar with dispatch strategy and load following strategy, but the increasing trend is not slower than any of them, and the optimal value is net_use_rate $=0.3363$, where $E_{b \max }=2500 \mathrm{~kW}$ and $\mathrm{Vol}_{b}=15500 \mathrm{kWh}$; furthermore, there is a fast increasing to the value of net-use rate as the increasing of rated power when BESS capacity is fixed. The reason why Figure 9(c) has so apparently diversifications as BESS parameters changes is mainly decided by the BESS strategy.

Sensitive analysis results from Figure 6 to Figure 9 indicate that the performance of multistage dispatch strategy is more stable and outstanding than the other strategies. 


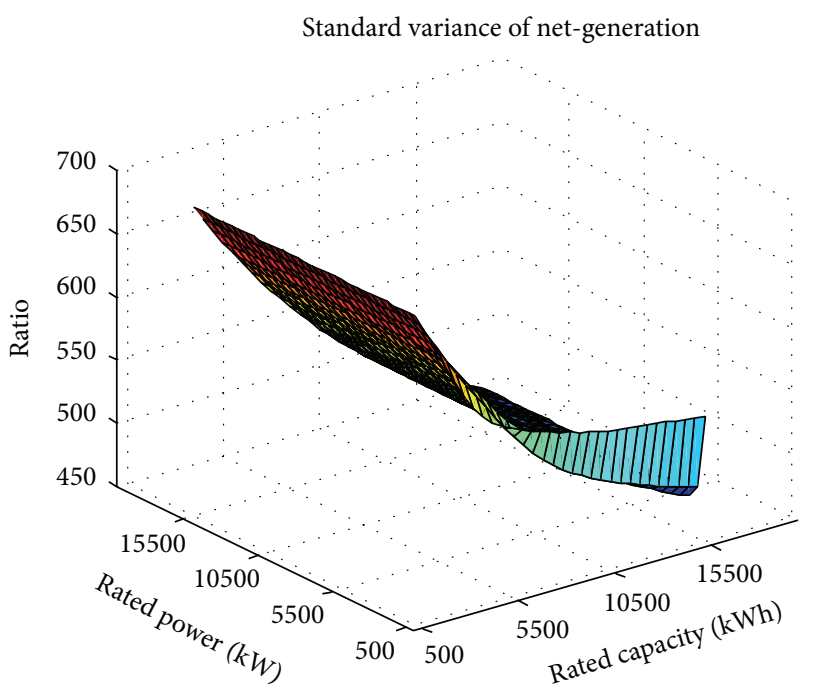

(a)

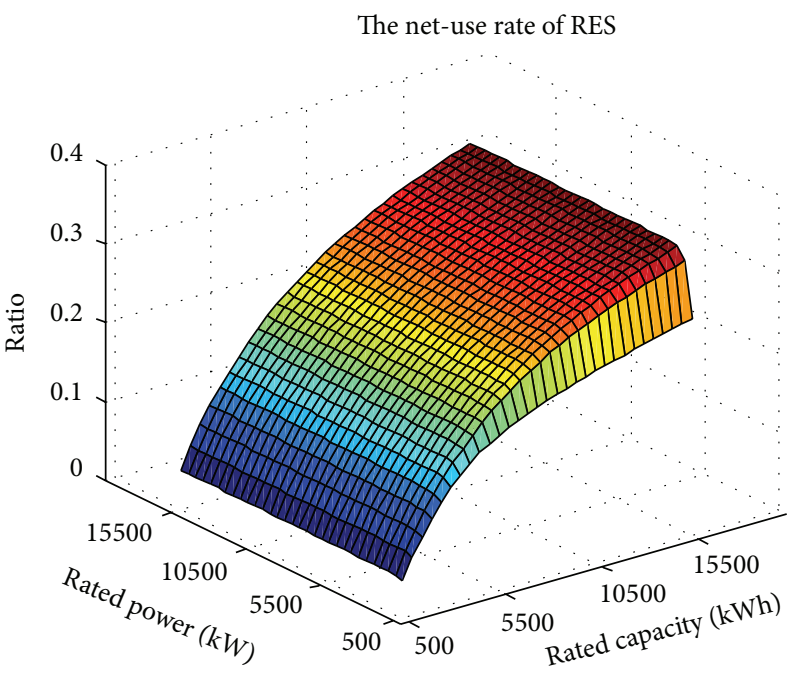

(b)

The use rate of BESS

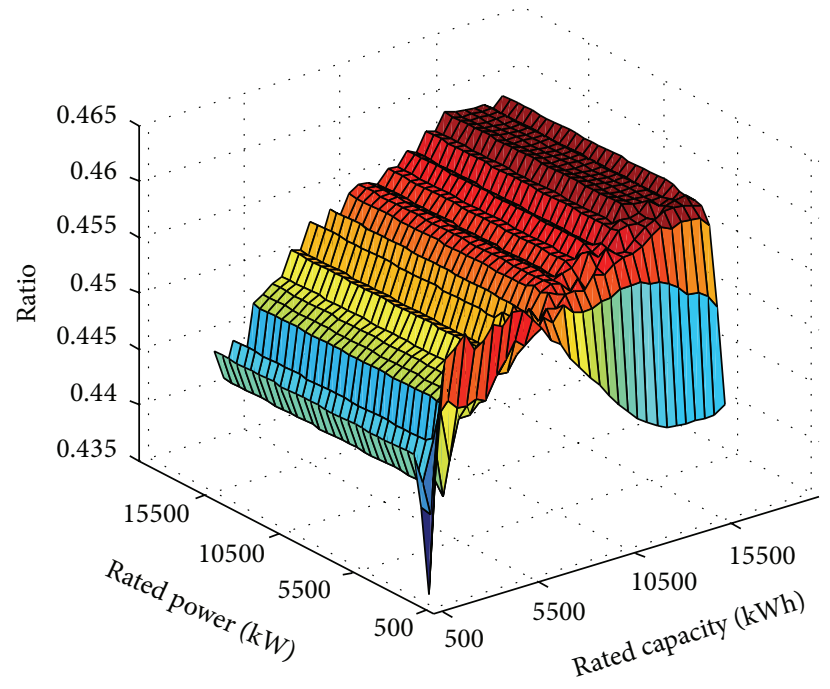

(c)

FIGURE 7: Performance of load following dispatch strategy with different levels of BESS parameters. (a) Standard variance of net-generation at PCC. (b) Net-use rate of RES in HES. (c) BESS use rate.

From the index of standard variance var we could observe that to power fluctuation smoothing, the improving rate of multistage dispatch strategy is faster and more stable, and the load following strategy has better performance than the two other strategies. To the indicator of net_use_rate, load following strategy has the best performance than other strategies, but gap between the value of load following strategy and multistage dispatch strategy is very small and will be smaller and smaller if BESS size increases. The indicator of peak power in HES $P_{\text {peak }}$ is not discussed in this case study, and because the advantages of multistage dispatch strategy are so significant, no detailed experiments should be done.

In generally, the performance of BESS in mitigating power fluctuation caused by high penetration of RES integration will be better and better as the BESS rated capacity grows, but the optimal rated power has big difference with the specific strategy. If we could fully analyze the relationships among BESS parameters and forecast uncertainty levels and power smoothing performance, an optimal sizing of BESS could be determined, also a suitable operation strategy which combined performance of efficient and robust will be proposed according to the object of BESS. Furthermore, the results of case study obtained in this paper could be utilized in economy or/ and reliability analysis.

\section{Conclusions}

In this paper a novel multistage dispatch strategy is proposed for alleviating fluctuation and improving power quality of HES, which integrates high penetration level of RES, which 


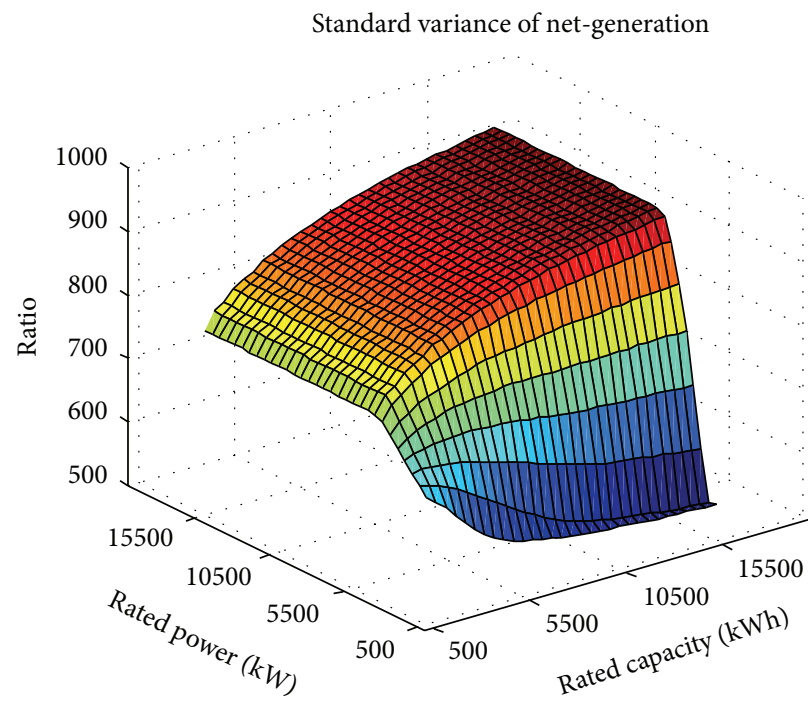

(a)

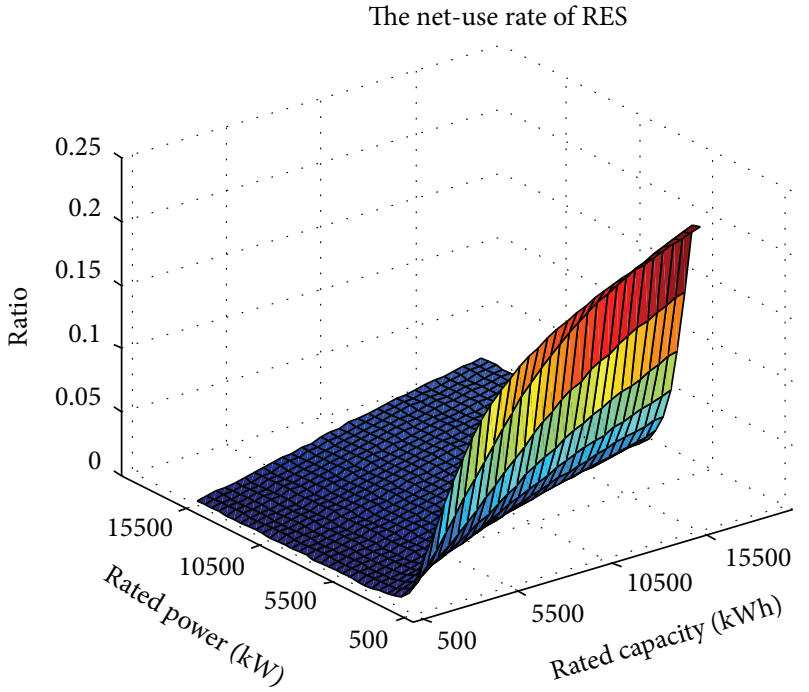

(b)

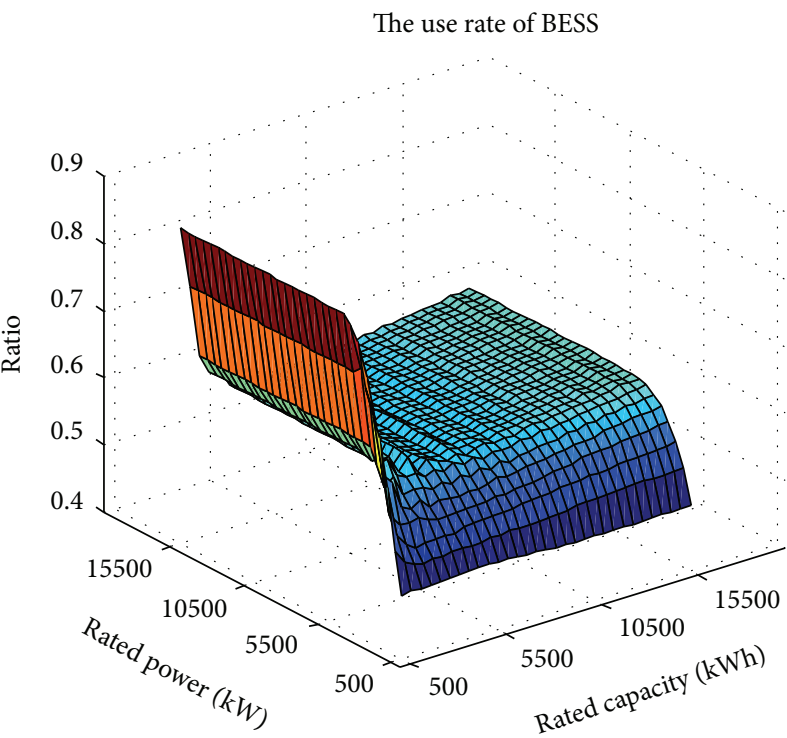

(c)

FIGURE 8: Performance of maximum charging dispatch strategy with different levels of BESS parameters. (a) Standard variance of netgeneration at PCC. (b) Net-use rate of RES in HES. (c) BESS use rate.

could decide when and how much should the BESS be charged or discharged. This approach is consisted with two main parts; preoptimize the BESS operation day-ahead by predicted data of RES generation (wind, PV) and load demand with modified dynamic programming algorithm, and dynamically adjust the BESS actual operation with heuristic dispatch control combined with hysteresis band based on real-time HES data. Four other conventional BESS operation strategies also have been discussed in different cases for evaluating the performance of the multistage dispatch strategy. First, we assume perfect knowledge of the HES state and forecast data, the simulation results show that the approach proposed in this paper has better performance both in duration of one day and one year long. Further, we analyze the availability of strategies to cope with inevitable disturbance and forecast errors and also discuss the impact of BESS parameters on power smoothing performance of the HES; simulation results demonstrate that the strategy proposed in this paper is more robust and economic than other strategies.

Future work will be focused on relaxing our assumption so as to include forecast uncertainty modeling and state estimation, and considering more elements in HES, such as controllable loads and real-time price, and should include some other problems such as unit commitment problem, economic dispatch problem, and so on. 


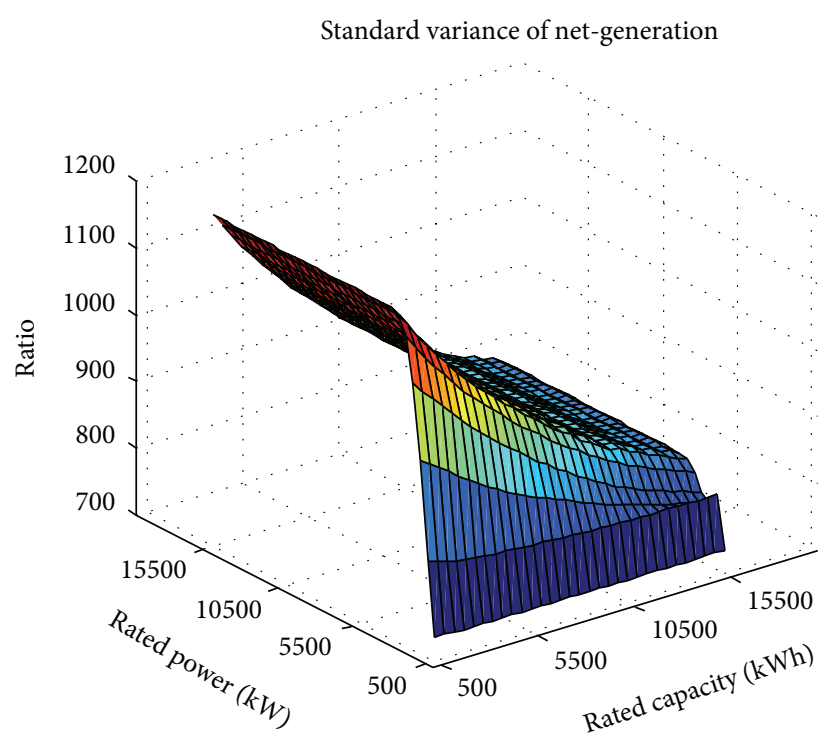

(a)

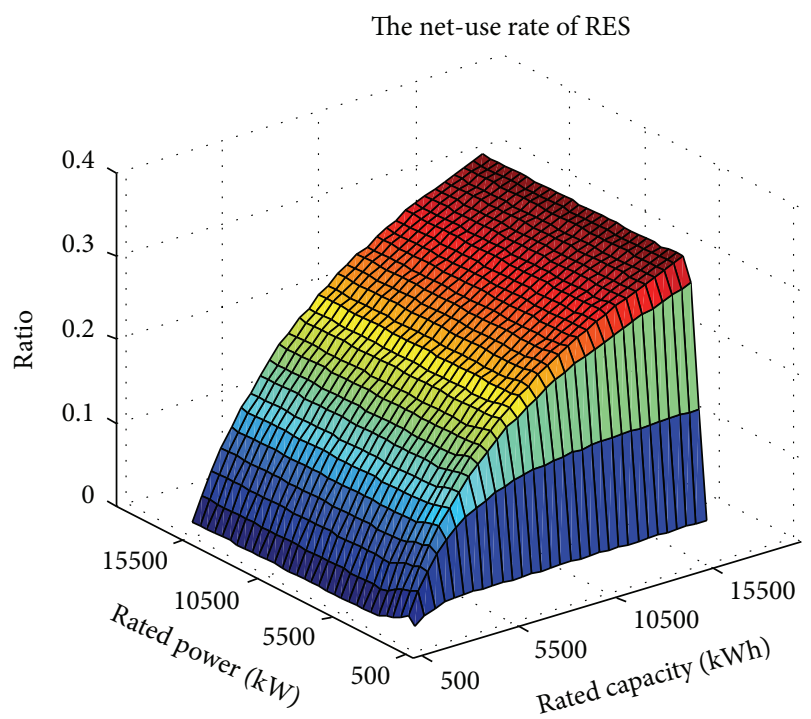

(b)

The use rate of BESS

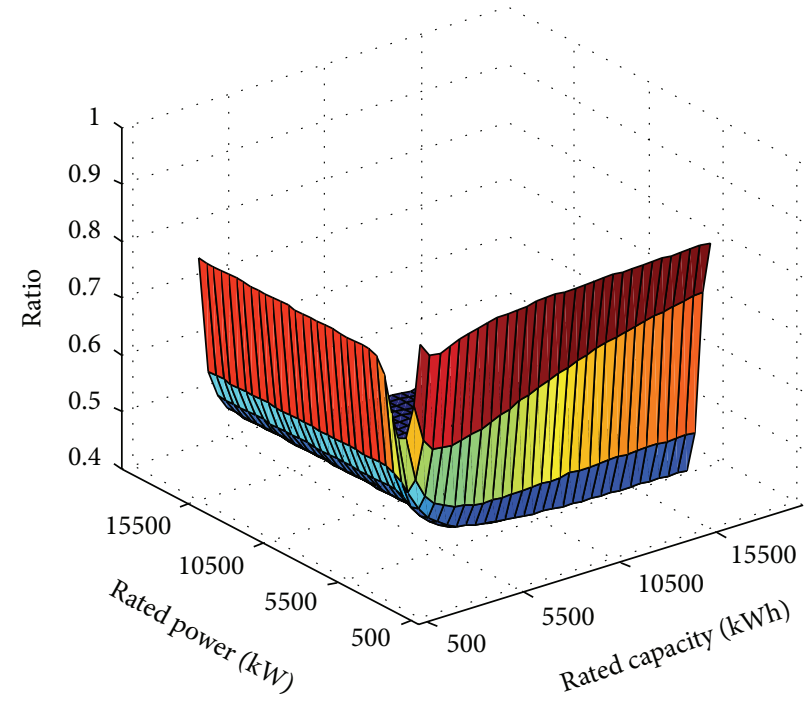

(c)

FIGURE 9: Performance of maximum dispatch discharging strategy with different levels of BESS parameters. (a) Standard variance of netgeneration at PCC. (b) Net-use rate of RES in HES. (c) BESS use rate.

\section{Nomenclature}

\section{Variables}

$P_{\text {wind }}(k)$ : Aggregate power generated by wind generators in period $k(\mathrm{~kW})$

$P_{\text {solar }}(k)$ : Aggregate power generated by PV generators in period $k(\mathrm{~kW})$

$P_{\text {grid }}(k)$ : Power imported from or exported to the external grid in period $k(\mathrm{~kW})$

$P_{\text {load }}(k): \quad$ Real-time load of HES in period of $k(\mathrm{~kW})$

$\operatorname{Vol}_{b}(k)$ : Capacity of BESS in period $k(\mathrm{kWh})$

$P_{\text {preload }}(k)$ : Predicted load demand in period $k$ when doing day-ahead forecast $(\mathrm{kW})$
$P_{\text {prewind }}(k)$ : Predicted wind generation power in period $k$ when doing day-ahead forecast $(\mathrm{kW})$

$P_{\text {presolar }}(k)$ : Predicted PV generation power in period $k$ when doing day-ahead forecast $(\mathrm{kW})$

$P_{b \text { pre }}(i)$ BESS charging or discharging power in period $k$ when doing day-ahead programming $(\mathrm{kW})$

level $(k)$ : An auxiliary variable, used for controlling real-time BESS operation

$\mathrm{Vol}_{b}: \quad$ BESS capacity limit (rated capacity) (kWh)

$P_{b}(k)$ : $\quad$ Real-time BESS charge or discharge power in period $k(\mathrm{~kW})$

$P_{b \max }: \quad$ maximum charging power limit of BESS $(\mathrm{kW}), P_{b \max }>0$ 
$Y(k): \quad$ Net-generation of HES in period $k(\mathrm{~kW})$

$v(k): \quad$ Wind speed in period $k(\mathrm{~m} / \mathrm{s})$

$G_{\mathrm{bt}}(k): \quad$ Illumination intensity in period $k\left(\mathrm{~kW} / \mathrm{m}^{2}\right)$

$Y_{\text {pre }}(k)$ : Predicted net-generation power in period $k$ when doing day-ahead forecast (kW)

$\operatorname{Vol}_{\text {pre }}(k)$ : BESS capacity in period $k$ when doing programming $(\mathrm{kWh})$

temp $(k)$ : Forecast error of HES net-generation in period $k$ $(\mathrm{kW})$

$L_{\text {error }}(k)$ : Forecast uncertainty level of HES in period $k$.

\section{Parameters}

$v_{\mathrm{ci}}, v_{r}, v_{\mathrm{co}}: \quad$ Cut-in, rated, and cut-off wind speeds of wind turbines $(\mathrm{m} / \mathrm{s})$

$G_{\text {std }}$ : A special illumination intensity value $\left(\mathrm{kW} / \mathrm{m}^{2}\right)$

$R_{c}$ : $\quad$ Rated illumination intensity of $\mathrm{PV}$ generators $\left(\mathrm{kW} / \mathrm{m}^{2}\right)$

$\mathrm{Vol}_{b \text { min }}$ : Minimum available energy capacity of BESS (kWh)

T: $\quad$ Simulation horizon, namely, one whole year, $T=N \cdot M$

$Y_{\text {premax }}: \quad$ Maximum predicted net-generation power of one day when doing day-ahead forecast $(\mathrm{kW})$

$C_{\mathrm{HES}}, \Delta E_{\mathrm{HES}}$ : Hysteresis band factor and hysteresis band size

$E_{P, \max }: \quad$ Maximum forecast error percentage for future period $k$ of the next day

$\mathrm{Vol}_{b \text { max }}$ : $\quad$ Maximum available capacity of BESS (kWh)

$\Delta t: \quad$ The duration of two consequent periods, $\Delta t=15 \mathrm{~min}$

$P_{\text {grid }}$ max: $\quad$ Rated power of the transformer between HES and the external grid $(\mathrm{kW})$

$P_{\text {wind }}$ max: $\quad$ Rated power of wind turbines $(\mathrm{kW})$

$P_{\text {solar }}$ max: $\quad$ Rated power of PV generators $(\mathrm{kW})$

$N, M: \quad$ Number of periods of one day, and days of one year, respectively

$Y_{\text {premin }}$ : $\quad$ Minimum predicted net-generation power of one day when doing day-ahead forecast (kW)

$\varepsilon$ : An infinitely small positive value

$R_{P}$ : A random number which follows a uniform distribution

$\alpha, \beta$ : Coefficients of maximum and minimum available BESS capacity.

\section{Conflict of Interests}

The authors declare that there is no conflict of interests regarding the publication of this paper.

\section{References}

[1] A. Colmenar-Santos, S. Campíñez-Romero, C. Pérez-Molina, and M. Castro-Gil, "Profitability analysis of grid-connected photovoltaic facilities for household electricity self-sufficiency," Energy Policy, vol. 51, pp. 749-764, 2012.

[2] N. G. A. Hemdan and M. Kurrat, "Interconnection of decentralized renewable resources into distribution grids: Implications and planning aspects," Electric Power Systems Research, vol. 81, no. 7, pp. 1410-1423, 2011.

[3] L. Kevin, "A critical review of China's rapidly developing renewable energy and energy efficiency policies," Renewable and Sustainable Energy Reviews, vol. 29, pp. 508-516, 2014.

[4] International energy statistics EIA's Portal for Detailed Country and Regional Energy Data, 2010, http://tonto.eia.doe.gov/ cfapps/ipdbproject/IEDIndex3.cfm.

[5] M. A. Delmas and M. J. Montes-Sancho, "U.S. state policies for renewable energy: context and effectiveness," Energy Policy, vol. 39, no. 5, pp. 2273-2288, 2011.

[6] S. Wang, S. Gao, H. Li, and J. Luo, "Optimal selection of planning schemes for power grid with high penetration of intermittent generation," Power System Technology, vol. 37, no. 8, pp. 2129-2135, 2013.

[7] W. A. Omran, M. Kazerani, and M. M. A. Salama, "Investigation of methods for reduction of power fluctuations generated from large grid-connected photovoltaic systems," IEEE Transactions on Energy Conversion, vol. 26, no. 1, pp. 318-327, 2011.

[8] Q. Li, S. S. Choi, Y. Yuan, and D. L. Yao, "On the determination of battery energy storage capacity and short-term power dispatch of a wind farm," IEEE Transactions on Sustainable Energy, vol. 2, no. 2, pp. 148-158, 2011.

[9] A. Gupta, R. P. Saini, and M. P. Sharma, "Modelling of hybrid energy system-part II: combined dispatch strategies and solution algorithm," Renewable Energy, vol. 36, no. 2, pp. 466-473, 2011.

[10] Z. Jiang, L. Gao, and R. A. Dougal, "Adaptive control strategy for active power sharing in hybrid fuel cell/ battery power sources," IEEE Transactions on Energy Conversion, vol. 22, no. 2, pp. 507515, 2007.

[11] R. Luna-Rubio, M. Trejo-Perea, D. Vargas-Vázquez, and G. J. Ríos-Moreno, "Optimal sizing of renewable hybrids energy systems: a review of methodologies," Solar Energy, vol. 86, no. 4, pp. 1077-1088, 2012.

[12] A. Oudalov, R. Cherkaoui, and A. Beguin, "Sizing and optimal operation of battery energy storage system for peak shaving application," in Proceedings of the IEEE Lausanne POWERTECH, pp. 621-625, July 2007.

[13] M. Beaudin, H. Zareipour, A. Schellenberglabe, and W. Rosehart, "Energy storage for mitigating the variability of renewable electricity sources: an updated review," Energy for Sustainable Development, vol. 14, no. 4, pp. 302-314, 2010.

[14] Y. Xu, L. Xie, and C. Singh, "Optimal scheduling and operation of load aggregators with electric energy storage facing price and demand uncertainties," in Proceedings of the 43rd North American Power Symposium (NAPS '11), August 2011.

[15] S.-K. Kim, J.-H. Jeon, C.-H. Cho, J.-B. Ahn, and S.-H. Kwon, "Dynamic modeling and control of a grid-connected hybrid generation system with versatile power transfer," IEEE Transactions on Industrial Electronics, vol. 55, no. 4, pp. 1677-1688, 2008.

[16] S. Grillo, M. Marinelli, S. Massucco, and F. Silvestro, “Optimal management strategy of a battery-based storage system to improve renewable energy integration in distribution networks," IEEE Transactions on Smart Grid, vol. 3, no. 2, pp. 950958, 2012. 
[17] G. Bao, C. Lu, Z. Yuan, and Z. Lu, "Battery energy storage system load shifting control based on real time load forecast and dynamic programming," in Proceedings of the IEEE International Conference on Automation Science and Engineering: Green Automation Toward a Sustainable Society (CASE '12), pp. 815820, August 2012.

[18] R. Karki, P. Hu, and R. Billinton, "A simplified wind power generation model for reliability evaluation," IEEE Transactions on Energy Conversion, vol. 21, no. 2, pp. 533-540, 2006.

[19] J. Park, W. Liang, J. Choi, A. A. El-Keib, M. Shahidehpour, and R. Billinton, "A probabilistic reliability evaluation of a power system including solar/photovoltaic cell generator," in Proceedings of the IEEE Power and Energy Society General Meeting (PES '09), July 2009.

[20] S. Ge and H. Wang, "Reliability evaluation of distribution networks including distributed generations based on system state transition sampling," Automation of Electric Power Systems, vol. 37, no. 2, pp. 28-35, 2013.

[21] J. W. Taylor, P. E. McSharry, and R. Buizza, "Wind power density forecasting using ensemble predictions and time series models," IEEE Transactions on Energy Conversion, vol. 24, no. 3, pp. 775782, 2009.

[22] M. Negnevitsky, P. Mandal, and A. K. Srivastava, "Machine learning applications for load, price and wind power prediction in power systems," in Proceedings of the 15th International Conference on Intelligent System Applications to Power Systems (ISAP '09), November 2009.

[23] I. G. Damousis, M. C. Alexiadis, J. B. Theocharis, and P. S. Dokopoulos, "A fuzzy model for wind speed prediction and power generation in wind parks using spatial correlation," IEEE Transactions on Energy Conversion, vol. 19, no. 2, pp. 352-361, 2004.

[24] Y. Xu and C. Singh, "Adequacy and economy analysis of distribution systems integrated with electric energy storage and renewable energy resources," IEEE Transactions on Power Systems, vol. 27, no. 4, pp. 2332-2341, 2012.

[25] D. K. Maly and K. S. Kwan, "Optimal battery energy storage system (BESS) charge scheduling with dynamic programming," IEE Proceedings: Science, Measurement and Technology, vol. 142, no. 6, pp. 453-458, 1995.

[26] A. Parisio, C. del Vecchio, and A. Vaccaro, "A robust optimization approach to energy hub management," International Journal of Electrical Power and Energy Systems, vol. 42, no. 1, pp. 98-104, 2012.

[27] P. Harsha and M. Dahleh, "Optimal sizing of energy storage for efficient integration of renewable energy," in Proceedings of the 50th IEEE Conference on Decision and Control and European Control Conference (CDC-ECC '11), pp. 5813-5819, December 2011.

[28] P. Harsha and M. Dahleh, "Optimal sizing of energy storage for efficient integration of renewable energy," in Proceedings of the 50th IEEE Conference on Decision and Control and European Control Conference (CDC-ECC '11), pp. 5813-5819, December 2011.

[29] C.-T. Li, H. Peng, and J. Sun, "MPC for reducing energy storage requirement of wind power systems," in Proceedings of the American Control Conference (ACC '13), pp. 6607-6612, 2013.

[30] A. Parisio and L. Glielmo, "Energy efficient microgrid management using model predictive control," in Proceedings of the 50th IEEE Conference on Decision and Control and European Control Conference (CDC-ECC '11), pp. 5449-5454, December 2011.

[31] http://www.elia.be/en/about-elia. 


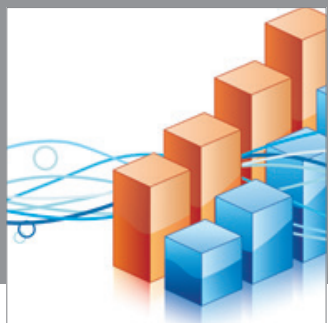

Advances in

Operations Research

mansans

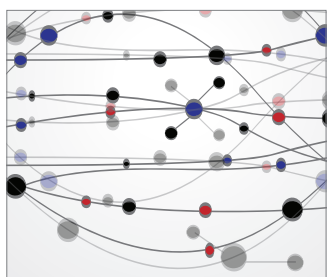

The Scientific World Journal
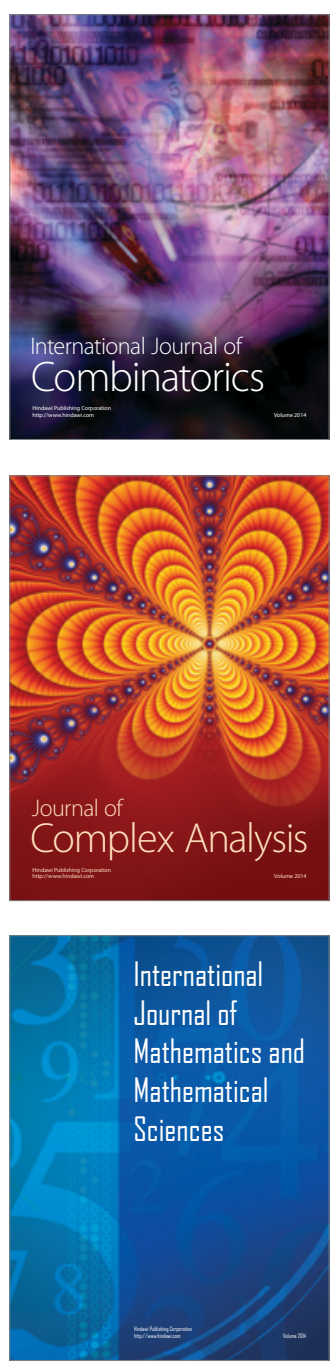
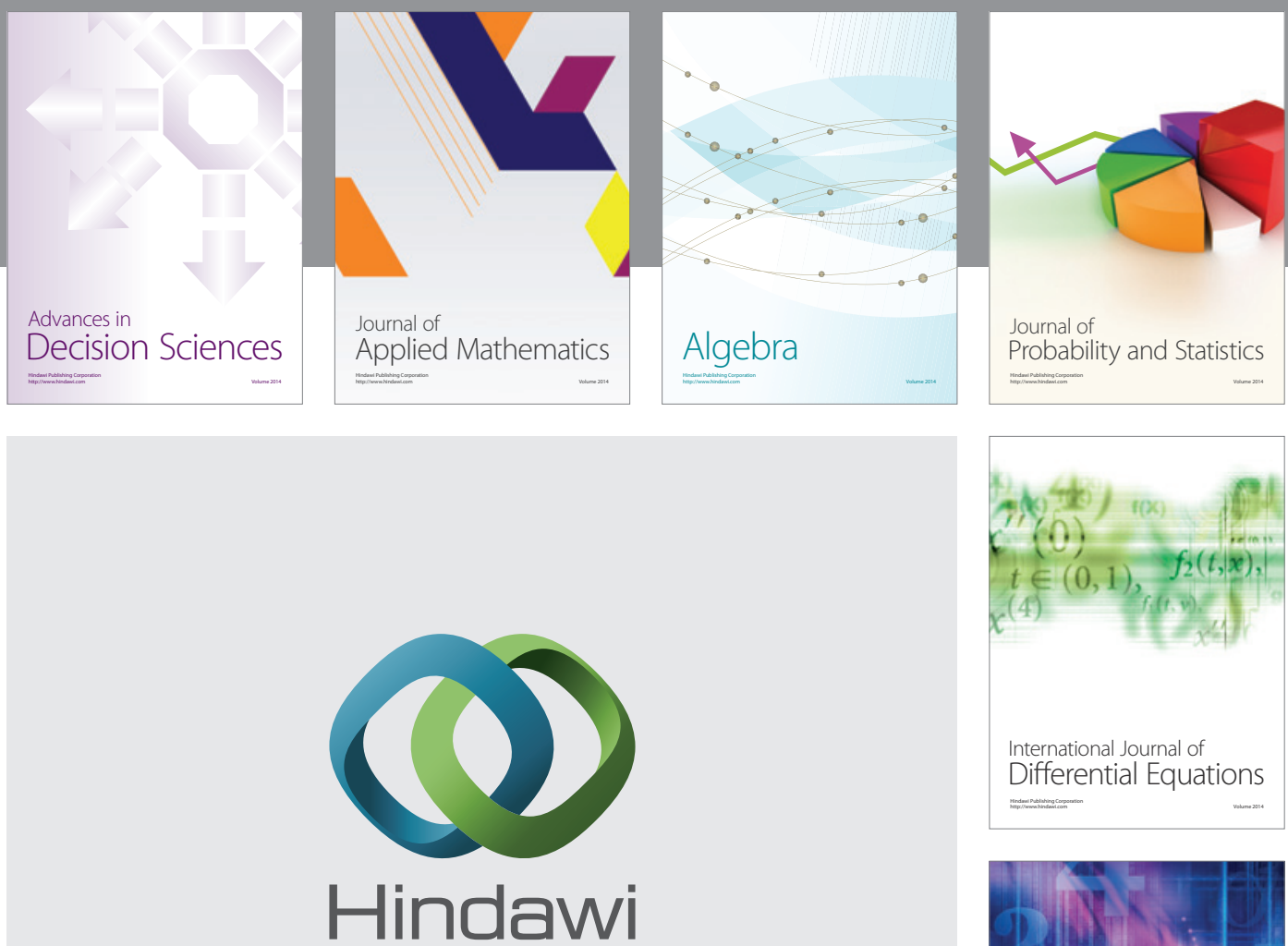

Submit your manuscripts at http://www.hindawi.com
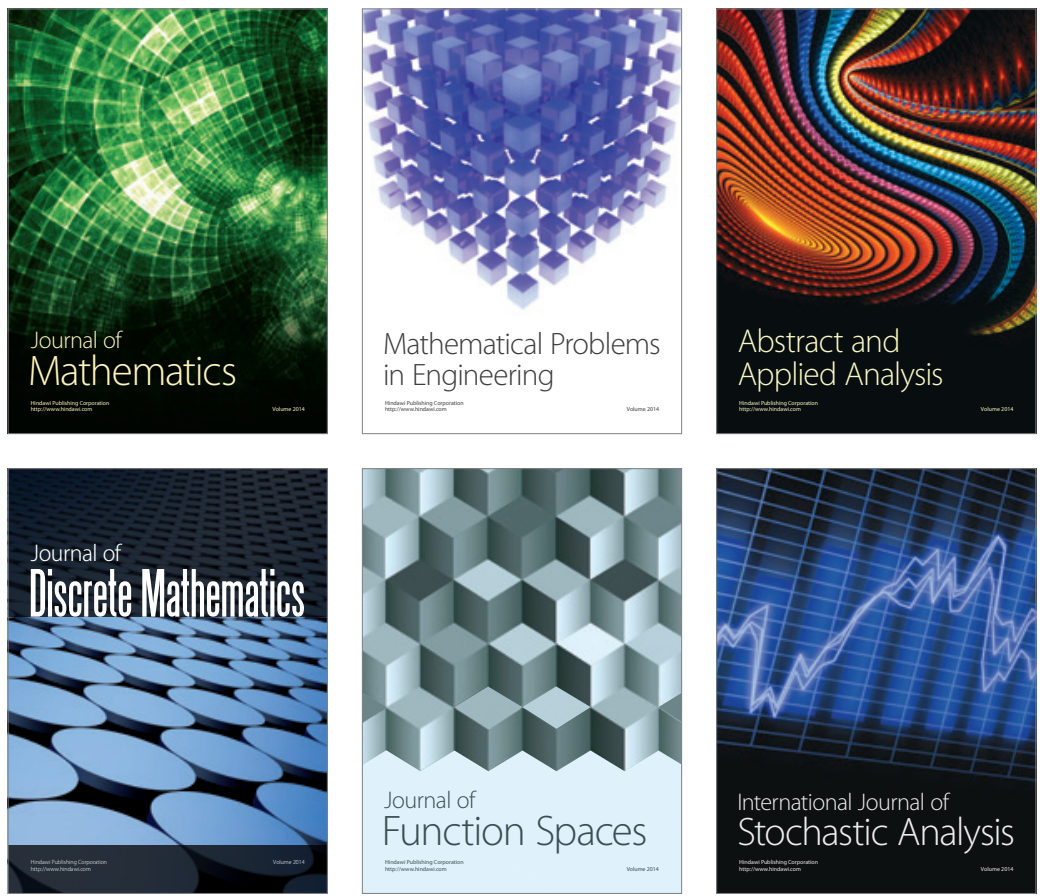

Journal of

Function Spaces

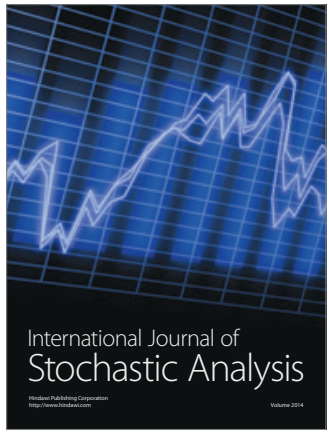

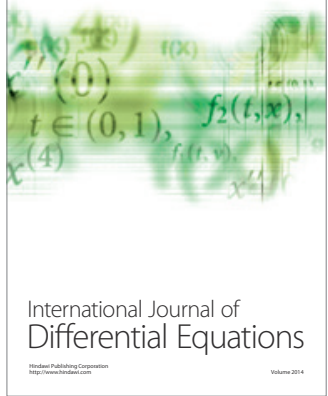
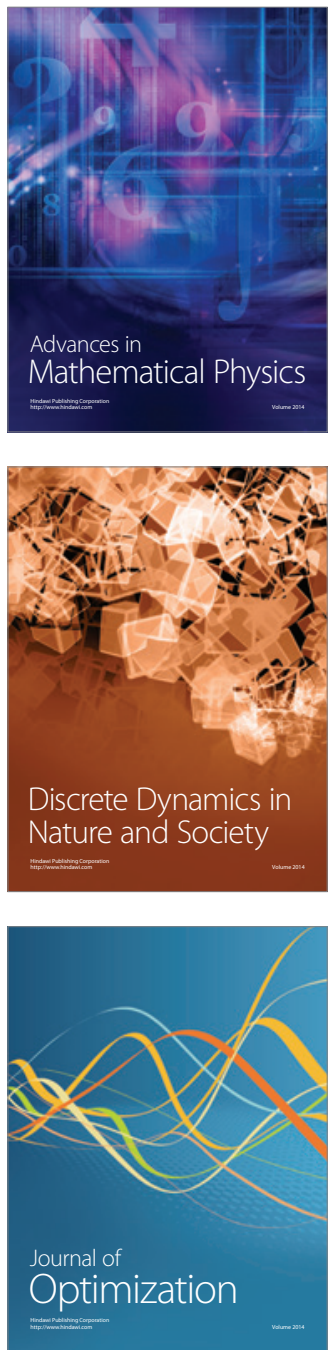